Research Article

\title{
Temporal Description of Annual Temperature and Rainfall in the Bawku Area of Ghana
}

\author{
Yaw Asamoah $\mathbb{D i D}^{1}$ and Kow Ansah-Mensah $\mathbb{D}^{2}$ \\ ${ }^{1}$ Department of Geography Education, University of Education, Winneba, Ghana \\ ${ }^{2}$ Department of Geography and Regional Planning, University of Cape Coast, Cape Coast, Ghana \\ Correspondence should be addressed to Yaw Asamoah; yasamoah@uew.edu.gh and Kow Ansah-Mensah; \\ kow.ansah-mensah@stu.ucc.edu.gh
}

Received 22 July 2019; Revised 4 November 2019; Accepted 5 February 2020; Published 1 April 2020

Academic Editor: Antonio Donateo

Copyright (c) 2020 Yaw Asamoah and Kow Ansah-Mensah. This is an open access article distributed under the Creative Commons Attribution License, which permits unrestricted use, distribution, and reproduction in any medium, provided the original work is properly cited.

\begin{abstract}
With varied implications, Ghana's temperature and rainfall are projected to rise and decline, respectively. A study exposing specific areas of concern for appropriate responses in this regard is a welcome one. This study sought to describe the temporal variations in temperature and rainfall in the Bawku Area of Ghana. A forty-year (1976-2015) daily climate data was collected on three meteorological stations from the Ghana Meteorological Agency. Normality test, homogeneity test, Standardised Precipitation Index (SPI) analysis, Mann-Kendall trend test, and One-way post hoc ANOVA were performed using XLSTAT and DrinC. Over the period under study, the mean annual rainfall pattern was generally erratic, fluctuating between $669.8 \mathrm{~mm}$ and $1339.4 .6 \mathrm{~mm}$ with an annual average of $935.3 \mathrm{~mm}$. The long-term (40-year period) average temperature of the three stations, on the other hand, was $28.7^{\circ} \mathrm{C}$, varying between $26.9^{\circ} \mathrm{C}$ and $29.9^{\circ} \mathrm{C}$ annually. Whereas the SPI value of 2006 was $\geq 2.0$, indicating extremely wet year with $2.3 \%$ probability of recurring once every 50 years, 1988 was the hottest year with temperature anomaly value of $1.2^{\circ} \mathrm{C}$, while coolest years were $1979\left(-1.8^{\circ} \mathrm{C}\right)$ and $1976\left(-1.0^{\circ} \mathrm{C}\right)$. The Mann-Kendall trend test showed a rise in rainfall in Binduri, Garu-Tempane, and Manga, yet none of the rainfall changes were statistically significant $(P>0.05)$. Mean temperature on the other hand experienced a significant rise $(P<0.05)$. With an R-square of $34.7 \%$, the rise in temperature in Manga witnessed the most significant change in annual temperature changes. There were statistically significant $(P<0.05)$ differences in the interdecadal temperature over the 40 -year period. Generally, it can be stated that both temperature and rainfall vary in the study area with various degrees of disparities, but temperature assumes an upward trend at a faster rate. We therefore recommend that stakeholders resort to the construction of dams and boreholes to ensure regular availability of water for both domestic and agricultural uses.
\end{abstract}

\section{Introduction}

Global climate is reported to have witnessed a drastic change at least over the last century as observed in the Intergovernmental Panel on Climate Change's (IPCC) fourth and fifth assessment reports. The effect of this change has resulted in the changes and shifts in the patterns of the climate elements, particularly precipitation, humidity, and temperature across the globe [1]. Accordingly, the Intergovernmental Panel on Climate Change reported that the global mean surface temperature has increased by $0.76^{\circ} \mathrm{C}$ in the last 150 years and will continue to witness an upward trend in the range of $1-6^{\circ} \mathrm{C}$ by the end of the $21^{\text {st }}$ century if nothing is done to mitigate it [2]. Global warming is described as the basis of climate change which the world is battling to resolve; these changes are extreme weather conditions, sea level rise, and a shift and erratic precipitation pattern observed in recent times [3]. Spatiotemporal trend analysis of precipitation on global scale has shown a slightly positive trend, though variability still exists on some regional and local scales in terms of intensity, amount, and shifts $[2,4]$. These variabilities and change in climate have significant impacts on livelihood and wellbeing of people, particularly those in rainfall-dependent regions. 
Climate variability and change pose serious threat to many countries, especially the most vulnerable and poor developing ones. United States Environmental Protection Agency [5] indicates that whereas there is still uncertainty in rainfall due to the shift and erratic nature, surface temperatures are continually rising and warming. Meanwhile, studies reveal that the combined effect of varying rainfall and rising temperatures is touted to affect all aspects of human activities [6]. Empirical evidence indicates that a rising trend in global temperature is the result of human activities contributing to the emission of atmospheric gases [7]. Even though every country around the globe contributes to the emission and consequently climate change, developed countries are reported to be the major contributors, yet the minor contributors, developing countries, are the more vulnerable to the eventual impacts [8].

Africa and West Africa by virtue of their geographical locations are much prone to the shocks of climate change, global warming, and the variability in climate. The IPCC report projects an increasing temperature trend in the West African region, within which Ghana is located, with emphasis on the area that lies within the Savannah and Sahel zone [9]. Rising temperatures and erratic precipitation have a dire consequence on the African population at large due particularly to its dependence on rainfall for its agricultural practices which in most cases is the major economic driver in the subregion [10]. This does not come with a surprise because, according to [11], temperature and rainfall are the main factors that directly affect agricultural activities. As such, erratic rainfall and extreme temperature may likely affect agricultural output in the continent, leading to further repercussions on the wellbeing of the people.

There have been studies in the recent past on trends in climate over Africa countries [3, 10, 12, 13]. These studies basically report on increasing temperatures over the continent and the fact that there are variations within countries. The authors separately found a significant rising trend in temperature, whereas rainfall on the other hand either insignificantly assumed an upward trend or was virtually constant. Regardless of their findings, it is more appropriate for research to also concentrate on local level trend analysis of climate variables since regional and national level studies have shown variability in climate. Moreover, local level adaptation measures to combating climate shocks are possible and effective only if the local level climate has been studied for possible variability and change as enshrined in the sustainable development goal (SDG) 13: take urgent action to combat climate change and its impacts.

In Ghana, projection of increasing trends of climate elements regardless of the variability indicates that the regions in the northern part of the country (Guinea and Sudan Savannah) will experience between 2.1 and $2.4^{\circ} \mathrm{C}$ of temperature increase, whereas all other regions will be between 1.3 and $2.0^{\circ} \mathrm{C}$ [14]. Holding all other factors constant, the Environmental Protection Agency has also indicated that historical trends in the climate of Ghana point to the fact that mean minimum and maximum temperatures in the Savannah areas are expected to increase by $1.10^{\circ} \mathrm{C}$ and $1.20^{\circ} \mathrm{C}$ by the year 2040 [15]. Researches into the trends of climate and its impacts have been carried out in the country, especially in the northern regions. These studies, including those in [16-19], independently concluded that the northern part will continually experience heating with short periods of rainfall.

Moreover, on the local scale, temperature and humidity are found to be increasing and decreasing, respectively, in the Bawku East Municipality of the Upper East Region (UER) [20]. The Ministry of Food and Agriculture (MoFA) of Ghana estimates that about $70 \%$ of the residents in the UER are farmers, mostly practicing rain-fed subsistence farming [21]. While it is undisputable fact that temperature and rainfall are the main direct determinants of agricultural activities [11, 22], especially in this part of the world, Frimpong et al. ignored rainfall trends and anomalies with the potential effects on the livelihoods of the poor farmers [20]. Hence, this study intends to fill that gap and add to literature. It is on the backdrop of the above that this study aims to analyse the trends of temperature and rainfall in the Bawku Area of UER of the Savannah agroclimatological zone of Ghana between 1976 and 2015.

\section{Materials and Methods}

2.1. Study Area. The Bawku Area of the Upper East Region is located in the north easternmost corner of Ghana and shares borders with two francophone countries, Burkina Faso and Togo, to the north and east, respectively. The area is made up of five different administrative districts: Bawku Municipality (Bawku), Bawku West (Zebilla), Binduri (Binduri), GaruTempane (Garu), and Pusiga District (Pusiga). The study area in totality is located on latitudes $10^{\circ} 30^{\prime}$ to $11^{\circ} 11^{1}$ north of the equator and longitudes $0^{\circ} 06^{\prime}$ east to $0^{\circ} 40^{\prime}$ west of the Greenwich Meridian with an average land area of about $2848 \mathrm{~km}^{2}$. The area lies between 202 and $235 \mathrm{~m}$ above sea level (Table 1). Bawku Municipality is found on latitudes $10^{\circ}$ $40^{\prime}$ to $11^{\circ} 11^{\prime}$ north of the equator and longitudes $0^{\circ} 61^{\prime}$ east to $0^{\circ} 18^{\prime}$ west, whereas Bawku West is located on latitudes $10^{\circ}$ $30^{\prime}$ and $11^{\circ} 10^{\prime}$ north and longitudes $0^{\circ} 20^{\prime}$ to $0^{\circ} 35^{\prime}$ west [23]. Binduri District on the other hand is on latitude $11^{\circ} 00^{\prime}$ north and longitudes $0^{\circ} 06^{\prime}$ east to $0^{\circ} 18^{\prime}$ west and GaruTempane is on latitudes $10^{\circ} 38^{\prime}$ to $11^{\circ} 00$ north and longitudes $0^{\circ} 06$ to $0^{\circ} 23^{\prime}$ east [24]. The study area map is shown in Figure 1.

Like the whole of UER, Bawku Area falls within the interior continental climate zone of Ghana dominated by long dry period and short wet (rainfall) period. The wet and dry seasons are determined by the North East Trade Winds (also called harmattan) and South West Monsoon that alternate with the seasons. North East Trade Winds originate from the Sahara Desert and control the climate of the area. In effect, the dry season lasts for seven months from October to April [20]. The wet season is characterized by a unimodal rainfall regime for about five months between May and September. The wet season, however, is influenced by the moisture concentrated tropical maritime air mass, which blows from the Atlantic Ocean [26]. The area is mainly drained by the White and Red Volta River and its tributaries together with other notable rivers and streams: Tamne and 
TABLE 1: Geographical locations of the meteorological stations with their elevations.

\begin{tabular}{lcccc}
\hline $\mathrm{S} / \mathrm{N}$ & Gauge station & Latitude $^{\circ}$ & Longitude $^{\circ}$ & Elevation $^{(\mathrm{m})}$ \\
\hline 1 & Binduri & 10.97 & -0.32 & 202 \\
2 & Garu & 10.85 & -0.18 & 202 \\
3 & Manga & 11.02 & -0.27 & 231 \\
\hline
\end{tabular}

Source: [20].

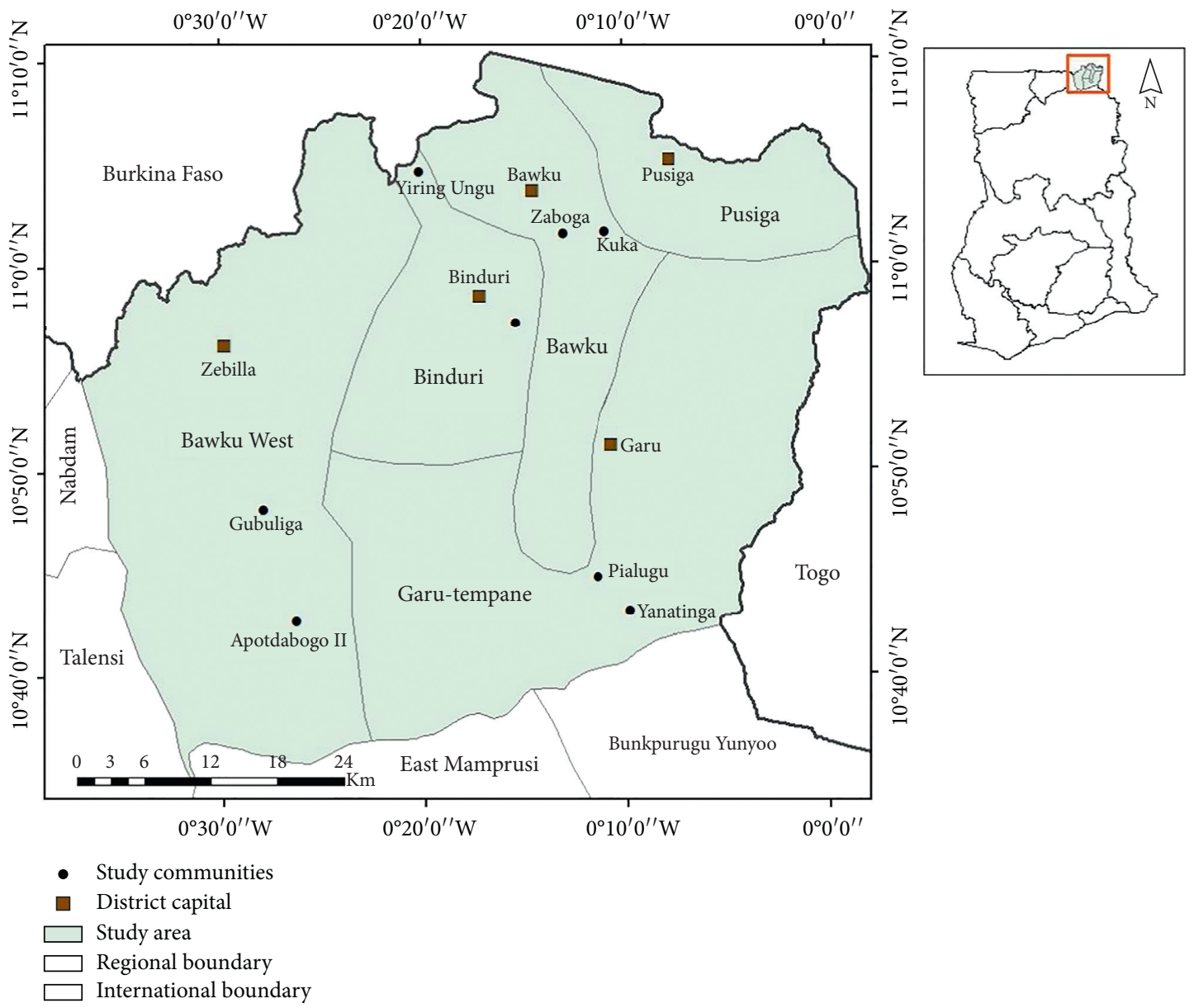

FIgURE 1: Study area map in regional and national context. Source: [25].

Pawnaba-Kiyinchongo, respectively. The rivers flow with the seasons (wet and dry). Rivers overflow their banks and flood nearby communities during the wet season (rainfall season); they, however, dry up during the dry season.

With a total population of about 384,151 , the area makes up about $36.7 \%$ of the UER population, with about $60 \%$ being females, $50 \%$ youth, $41 \%$ children under 15 , and about $9 \%$ aged [27]. The area is largely rural with average household size of 6.5 . About $60 \%$ of the population above 11 years are illiterate, while males constitute the majority (53.2\%) of the $43 \%$ literates. The largest ethnic group found in the area is the Kussasis of the Mole Dagbani group; there are also the Mamprusis, Moshies, Bimoba, Bisas, Busanga, Frafra, and Fulani. The dominant religion is Islam with majority of the Christian population being Catholics and there are also some Traditional African Religious worshipers. Whereas the predominantly rural population found in the area practices subsistence agriculture, the commonest economic activity there is primary (agriculture, forestry, and fishing) and a few secondary (wholesale, retail, and manufacturing) [21, 27].

2.2. Dataset. Time-series data of rainfall and temperature for the three meteorological stations at Binduri, Garu-Tempane, and Manga communities, all in the Bawku Area of the Upper East Region were collected and analysed for the period from 1976 to 2015 . Table 1 presents the geographical locations and elevation of the instruments used to record the data. The forty-year-period data was used because of its consistency, accuracy, and reliability. This highly dependable station data was collected from the Ghana Meteorological Agency (GMet) in Accra, which is mandated to collect and store climate data. Spatial interpolation of data was carried out to 
fill data gaps using arithmetic mean method where data before and after the gap were used to generate the missing value. Consequently, years without consistent data were then eliminated from the study, hence the 1976-2015 data. The monthly and annual data used for the analysis in this study were compiled from the daily data collected. The overall average of the 40-year period was calculated to be able to examine the rainfall and temperature anomalies.

2.3. Data Analysis. The first part of the data analysis was done using normality test statistics to understand the nature of the data. This was necessary to determine the best available test tools suitable for the analysis. As such, both rainfall and temperature data were subjected to normality test using Shapiro-Wilk, Anderson-Darling, Lilliefors, and Jarque-Bera tests. These tests were applied because of their suitability and general acceptability for normality testing [28] and the fact that each of the tests will complement the others' weaknesses. With a null hypothesis of normal sample distribution, all the aforementioned tests compare test scores of sample to normally distributed scores with the same standard deviation and mean. Equations used for the normality tests are provided.

Shapiro-Wilk $(W)$ is given as

$$
W=\frac{\left(\sum_{i=1}^{n} a_{i} x_{(i)}\right)^{2}}{\sum_{i=1}^{n}\left(x_{i}-\bar{x}\right)^{2}}
$$

where $x_{1}$ is the ordered sample value, $a_{i}$ is a constant generated from the means, variances, and covariance of the ordered statistics, $n$ is number of observations, and $\bar{x}$ is the sample mean.

Anderson-Darling $(A D)$ test uses cumulative distribution function to determine the normality of a given set of data. The formula is shown:

$$
\mathrm{AD}=-n-\frac{1}{2} \sum_{i=1}^{n}(2 i-1)\left[\ln F\left(x_{i}\right)+\ln \left(1-F\left(x_{n-i+1}\right)\right)\right] \text {, }
$$

where $n$ =sample size; $F(x)$ is the cumulative distribution function for the specified distribution; $i$ is the $i^{\text {th }}$ sample when the data is sorted in ascending order.

Lilliefors is an improvement in the Kolmogorov-Smirnov (K-S) test correcting the tails of the probability distributions. One of its main advantages is that even when mean and standard deviations are unknown, the test can still be applied. The formula is shown as follows:

$$
Z_{i}=\frac{x_{i}-\bar{x}}{s}, \quad i=1,2, \ldots, n,
$$

where $Z_{i}$ is the individual $z$-score for every member in the sample; $X_{i}$ is an individual member/data point.

The Lilliefors test statistic which is the empirical distribution function is then given by

$$
T_{1}=\sup _{x}\left|F^{*}(x)-S(x)\right|
$$

where $F^{*}$ is the standard normal distribution function; $S(x)$ is the empirical distribution function of the $Z_{i}$ values.

Jarque-Bera (JB) test is a goodness-of-fit test of whether sample data have the skewness and kurtosis matching a normal distribution. JB test is given by the following formula:

$$
\begin{aligned}
K_{3} & =\frac{\sum_{i=1}^{n}\left(x_{i}-\bar{x}\right)^{3}}{n s^{3}}, \\
K_{4} & =\frac{\sum_{i=1}^{n}\left(x_{i}-\bar{x}\right)^{4}}{n s^{4}}-3 .
\end{aligned}
$$

The Jarque-Bera test is then determined by putting together equations (5) and (6).

$$
\mathrm{JB}=n\left(\frac{\left(K_{3}\right)^{2}}{6}+\frac{\left(K_{4}\right)^{2}}{24}\right)
$$

where $x$ is each observation, $n$ is the sample size, $s$ is the standard deviation, $k_{3}$ is skewness, and $k_{4}$ is kurtosis.

Secondly, homogeneity test statistics were applied to determine homogenous nature of the data prior to analysing the trend. Homogeneity test was carried out to test for homogeneity and suitability of data for trend testing using Pettitt's test, Standard Normal Homogeneity Test (SNHT), and the Buishand range test [29]. These three tests have similar null hypothesis $\left(\mathrm{H}_{0}\right)$ that data is homogenously identical. At a $P$ value of $0.05, \mathrm{H}_{0}$ is accepted or rejected.

2.3.1. Pettitt's Test. This test is a nonparametric test based on rank $r_{\mathrm{i}}$ of $Y_{i}$ and requires no assumption about the distribution of data [29].

$$
T_{y}=2 \sum_{t-1}^{y} r_{i-y(n+1), y=1,2, \ldots, n} .
$$

That is, there is a break in year $k$ when

$$
T_{\bar{k}}=\max _{0 \leq x \leq 1} T_{y} .
$$

The value of $T_{k}$ is then compared with the [29] critical value.

2.4. Standard Normal Homogeneity Test (SNHT). $\bar{z}_{1}$ represents a statistic comparison of the mean of the first $y$ years with the last years of $n-y$ using $P(y)$.

$$
P y=y \overline{Z 1}+(n-1) \overline{Z 2}, \quad y=1,2,3 \ldots n,
$$

where

$$
\begin{aligned}
& \overline{Z 1}=\frac{1}{y} \sum_{i-1}^{n} \frac{y_{i}-\bar{y}}{s}, \\
& \overline{Z 2}=\frac{1}{n-y} \sum_{i-y+1}^{n} \frac{y_{i}-\bar{y}}{s} .
\end{aligned}
$$


The year $y$ consisted of break if value of $P$ is maximum. Thus, the null hypothesis is rejected if

$$
P_{o}=\max _{0 \leq y \leq 1} P_{y} .
$$

2.4.1. Buishand's Test. Buishand's test is applied to variables of any distribution. However, properties of the test have especially been studied for normal distribution case [29]. The homogeneity test, however, can be based on the cumulative deviations from the mean and hence is given by the following formula [30]:

$$
S_{o}^{*}=O, S_{K}^{*}=\sum_{i=1}^{k}(x i-u), \quad k=1,2, \ldots T .
$$

Thus, when the data is homogenous, the value of $S_{k}^{*}$ will rise and fall around zero. When $S_{k}^{*}$ is at its maximum or minimum, the year $y$ is said to have a break. Adjusted range $R$ is then obtained by

$$
R=\frac{\left(\max _{1 \leq t \leq T} S_{k}^{*}-\max _{1 \leq t \leq T} S_{k}^{*}\right)}{s} .
$$

Furthermore, a graphical analysis of the monthly and annual rainfall and temperature was performed to show the long-term variability in the dataset. The slope coefficient sign would then indicate whether the data follows a positive or negative trend. Temperature anomalies were calculated using the arithmetic mean. In this study, temperature anomaly is the number of degrees of temperatures that the absolute temperature varies from the average (reference point) or the difference of the absolute temperature from the average or baseline temperature.

To understand the interannual variability in the rainfall of the study area, the Standardised Precipitation Index (SPI) was used to calculate the anomalies in rainfall.

The SPI is generated using long-term records of precipitation. This is done by fitting the data into a probability distribution to be transformed into a normal distribution such that the mean value of the SPI for the location and its desired period is zero [31]. The SPI approach is a widely used method for precipitation or drought intensity studies. Results of SPI are originally generated using gamma distribution because of its suitability to precipitation time series [32]. However, one can also use the log-normal distribution approach in generating the SPIs as has been used by others (such as [33-37] because they produce similar results [38]). According to World Meteorological Organization, the SPI function is given by the following formula:

$$
I(i)=\frac{X_{i}-\bar{X}_{m}}{\sigma},
$$

where $I(i)$ is the standardised index of year $I ; X_{i}$ is the value for the year $I ; \bar{X}_{m}$ is the average for the year $i$; and $\sigma$ is the standard deviation of the time series.

The SPI can be calculated for different timescales such as $3,6,12,24$, and 48 months $[32,39]$. The SPI calculation was done using Drought Indices Calculator (DrinC); this stand-alone software has been used by others (such as $[38,40-42]$ ). Table 2 presents the interpretation of SPI results.

Subsequently, the Mann-Kendall (MK) trend test was applied in this analysis to the annual rainfall and temperature values to determine the statistical trend in the dataset. $\mathrm{MK}$ is a monotonic nonparametric test that is widely used for trend testing in climate data [43]. In this test, the null hypothesis $\left(\mathrm{H}_{0}\right)$ is that there is no trend in the dataset. A positive and negative MK test result signifies an increasing and decreasing trend, respectively, and this was supported by Sen's slope estimator test. Sen's slope estimator, on the other hand, is used to complement the MK test and also shows the magnitude of the trend. The closer the result is to zero (0), the lesser the trend is. The sign (+, - ) of the slope tells if the trend is increasing or decreasing. The MK was adopted because of its robustness and generally acceptability and consequent application in many climate analyses [44].

According to Tigkas et al., MK test statistics are calculated based on the following equations [38]:

$$
\begin{gathered}
S=\sum_{i=1}^{x-1} \sum_{j=i+1}^{x} \operatorname{Sgn}(x j-x i), \\
\operatorname{Sgn}(x)= \begin{cases}+1, & \text { if } x j-x k>0, \\
0, & \text { if } x j-x k=0, \\
-1, & \text { if } x j-x k<0 .\end{cases}
\end{gathered}
$$

$X i$ and $X k$ are the annual values in years $j$ and $k(j>k)$, respectively.

Variance is given as follows:

$$
\operatorname{Var}(S)=\frac{n(n-1)(2 n+5)}{18},
$$

where $n$ is the number of observations and $x i(i=1, \ldots, n)$ are the independent observations.

$Z$-statistics:

$$
\begin{cases}\frac{s-1}{\sqrt{\operatorname{Var}(S)}}, & \text { if } s>0, \\ 0 \ldots, & \text { if } s=0 \\ \frac{s+1}{\sqrt{\operatorname{Var}(s)}}, & \text { if } s<0 .\end{cases}
$$

Sen's slope is estimated by the following formula [38]:

$$
Q i=\frac{(X j-X k)}{j-k}, \quad \text { for } i=1, \ldots N
$$

But $X_{j}$ and $X_{k}$ are data values at times $j$ and $k ; j$, however, is greater than $k(j>k)$.

$\mathrm{N}$ is the slope estimator; if there is just one piece of data in each time, then $\mathrm{N}$ is given as 
TABLE 2: SPI values.

\begin{tabular}{|c|c|c|c|}
\hline SPI results & Interpretation & Probability of occurrence & Severity of event \\
\hline$\geq 2.0$ & Extremely wet & 2.3 & 1 in 50 years \\
\hline 1.5 to 1.99 & Very wet & 4.4 & 1 in 20 years \\
\hline 1.0 to 1.49 & Moderately wet & 9.2 & 1 in 10 years \\
\hline 0.0 to 0.99 & Mildly wet (NN) & 34.1 & 1 in 03 years \\
\hline 0.0 to -0.99 & Mildly dry (NN) & 34.1 & 1 in 03 years \\
\hline-1.0 to -1.49 & Moderately dry & 9.2 & 1 in 10 years \\
\hline-1.5 to -1.99 & Very dry & 4.4 & 1 in 20 years \\
\hline$\leq-2.0$ and less & Extremely dry & 2.3 & 1 in 50 years \\
\hline
\end{tabular}

NB: "NN" means near normal. Source: [39, 42].

TABLE 3: Normality test of temperature and rainfall data.

\begin{tabular}{|c|c|c|c|c|c|c|c|c|}
\hline \multirow{2}{*}{ Variable/test } & \multicolumn{2}{|c|}{ Shapiro-Wilk } & \multicolumn{2}{|c|}{ Anderson-Darling } & \multicolumn{2}{|c|}{ Lilliefors } & \multicolumn{2}{|c|}{ Jarque-Bera } \\
\hline & $\mathrm{W}$ & Sig. & $\mathrm{A}^{2}$ & Sig. & $\mathrm{D}$ & Sig. & JB obs. & Sig. \\
\hline \multicolumn{9}{|l|}{ Rainfall } \\
\hline Binduri & 0.8651 & 0.0002 & 1.1828 & 0.0038 & 0.1519 & 0.0209 & 63.6 & $<0.0001$ \\
\hline Garu-Tempane & 0.9144 & 0.0065 & 0.9878 & 0.0433 & 0.1133 & 0.2195 & 09.1 & 0.0010 \\
\hline Manga & 0.9220 & 0.0089 & 1.0403 & 0.0255 & 0.1092 & 0.2677 & 14.42 & 0.0007 \\
\hline \multicolumn{9}{|l|}{ Temperature } \\
\hline Binduri & 0.8017 & $<0.0001$ & 2.1485 & $<0.0001$ & 0.2058 & $<0.0002$ & 78.0280 & $<0.0001$ \\
\hline Garu-Tempane & 0.8089 & $<0.0001$ & 1.2330 & $<0.0029$ & 0.1393 & $<0.0489$ & 167.0084 & $<0.0001$ \\
\hline Manga & 0.7318 & $<0.0001$ & 2.1170 & $<0.0001$ & 0.1984 & $<0.0004$ & 301.9649 & $<0.0001$ \\
\hline
\end{tabular}

$$
N=\frac{n(n-1)}{2}
$$

where $n$ is the number of time periods.

Hence, Sen's estimator is given as

$$
\begin{cases}\frac{Q(N+1)}{2}, & \text { if } N \text { is odd, } \\ \frac{1}{2}\left(\frac{Q N}{2}+\frac{Q(N+2)}{2}\right) & \text { if } N \text { is even. }\end{cases}
$$

Lastly, One-way ANOVA post hoc test of multiple comparisons was applied to test for differences in means of the temperature and rainfall data. This test was introduced in this study to purposely complement trend test results while providing room to understand how best ANOVA could help understand the differences in mean scores of rainfall and temperature on decade bases. This was done by grouping the 40-year data into four groups (Group 1=1976-1985, Group 2=1986-1995, Group $3=1996-2005$, and Group $4=2006-2015$ ). It was to identify groups that cause the difference in temperature over the period.

\section{Results}

3.1. Normality Test Results for Rainfall and Temperature. Prior to undertaking the homogeneity and Mann-Kendall trend test, the data was subjected to normality test using Shapiro-Wilk, Anderson-Darling, Lilliefors, and Jarque-Bera tests. All four tests have similar null $\left(H_{\mathrm{o}}\right)$ and alternate $\left(H_{\mathrm{a}}\right)$ hypotheses; data follows normal distribution and data does not follow normal distribution, respectively. Probability was taken at $95 \% ; H_{\mathrm{o}}$ is accepted at $P>0.05$ and rejected at $P<0.05$. Table 3 and Figure 2 show tests statistics and graphical results of the normality test.

Regarding the temperature, it is observed from Table 3 that all four test tools at all three gauge stations show significant deviation from normal distribution with $P$ values $\leq 0.05$; hence, $H_{\mathrm{o}}$ is rejected. The risk of rejecting $H_{\mathrm{o}}$ while it is true varies from $0.01 \%$ to $4.89 \%$. In relation to temperature data, the risk of type 1 error is minimal using Shapiro-Wilk and Jarque-Bera test tools as compared to the others. Meanwhile, with rainfall data, all four tests violate the normality assumption with $P$ value $\leq 5 \%(P<0.05)$.

Consequently, the null hypothesis for all four tests at Binduri was rejected, whereas one (Lilliefors) each was rejected for both Garu and Manga. That is, only Lilliefors test indicated that Garu and Manga rainfall data were normally distributed. P-P plots and Q-Q plots are shown in Figure 2 for visual inspection of the normality test. The risk of type 1 error, however, ranges between $0.01 \%$ and $4.33 \%$. Thus, the results imply that both rainfall and temperature data violate the normality assumption and hence cannot be subjected to a parametric test analysis.

3.2. Homogeneity Test Analysis. In this study, three types of homogeneity test (i.e., Pettitt's test, the SNHT test, and Buishand's test) were performed at $5 \%$ level of significance. This test is used to determine if indeed the datasets are significantly homogenous for the trend test analysis.

In Figure 2, whereas SNHT and Buishand's test detected the same change point $(T)$ during 2007 at both Binduri and Garu-Tempane, Pettitt's test was met with a 

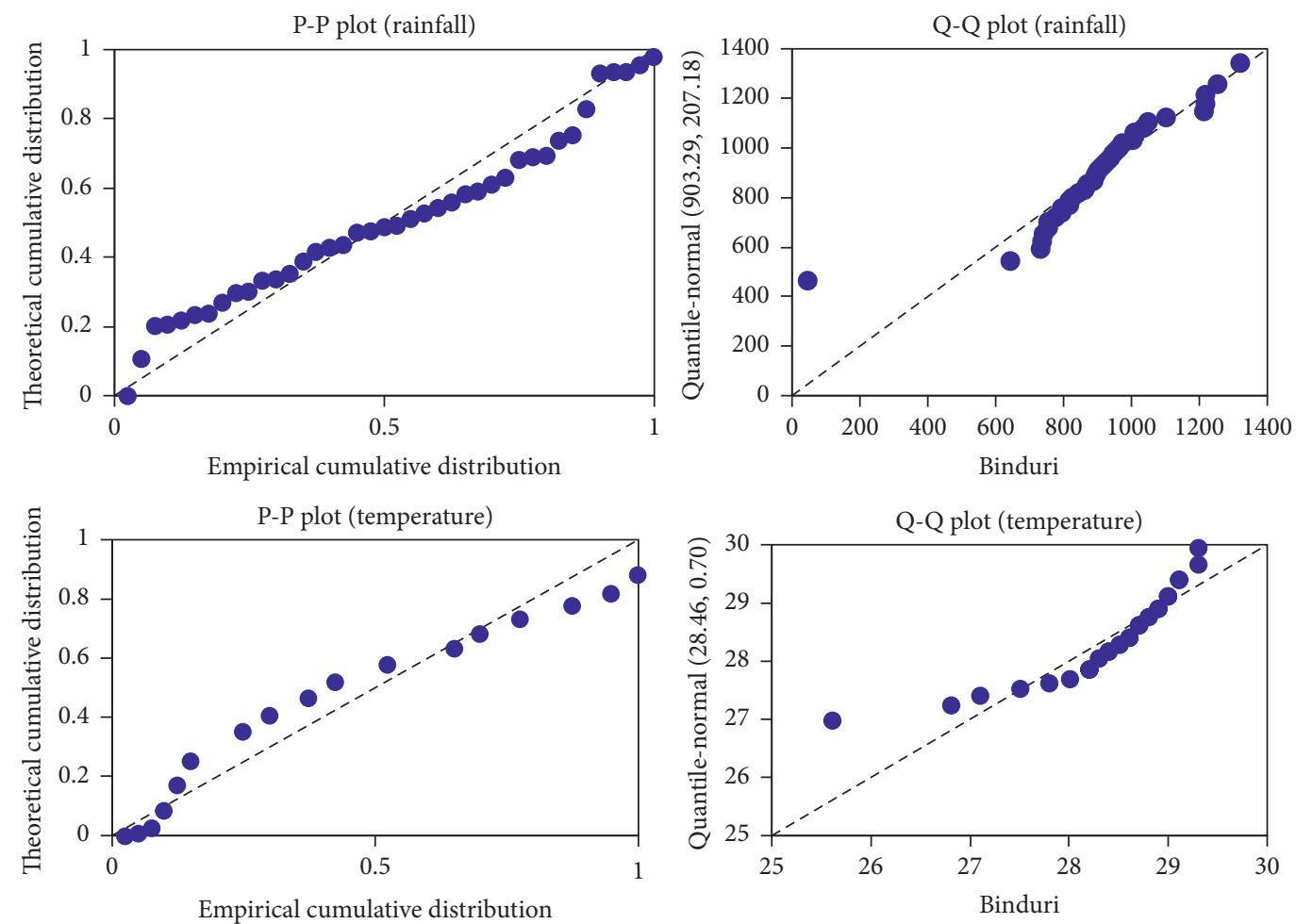

(a)
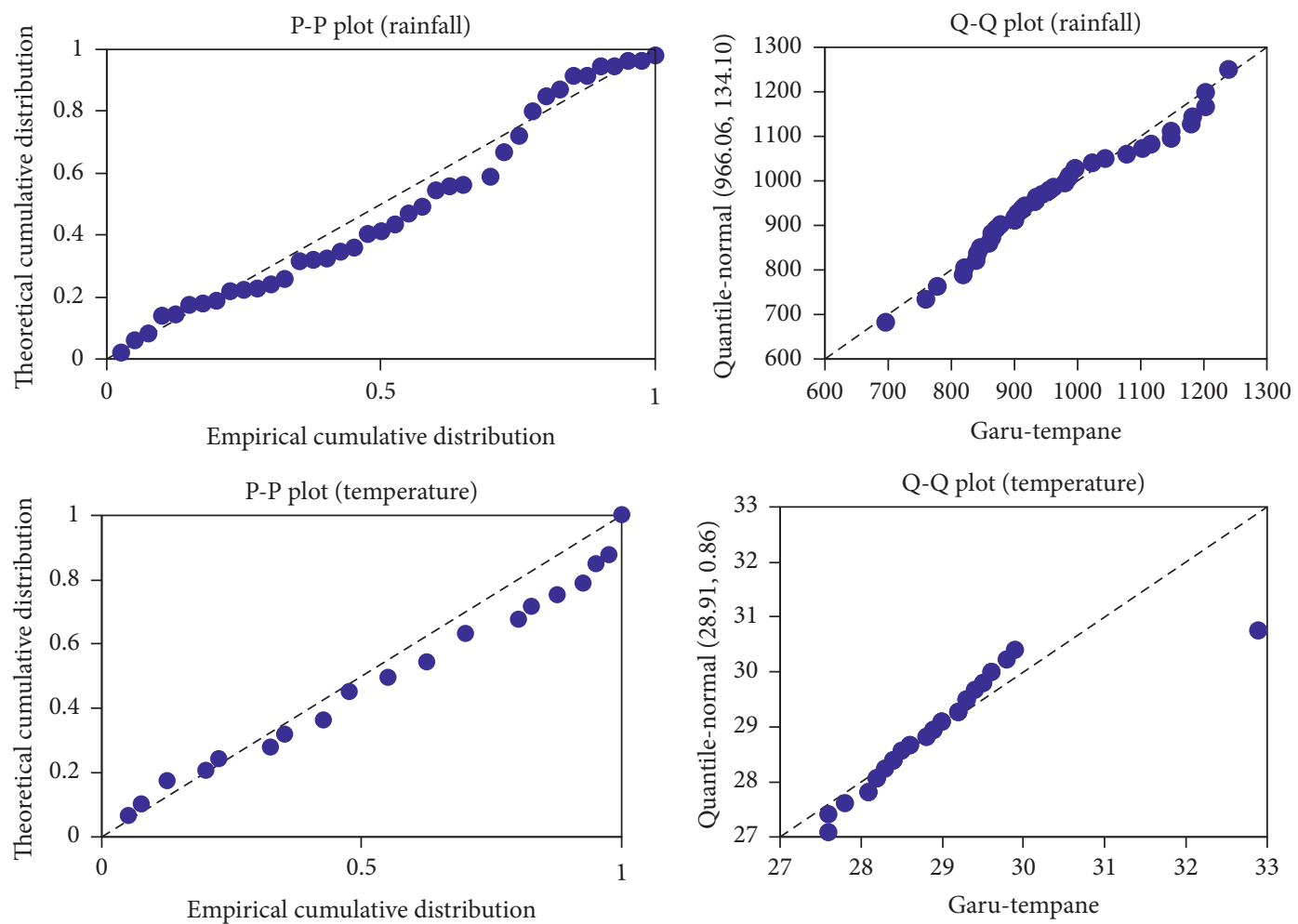

(b)

FIgUre 2: Continued. 

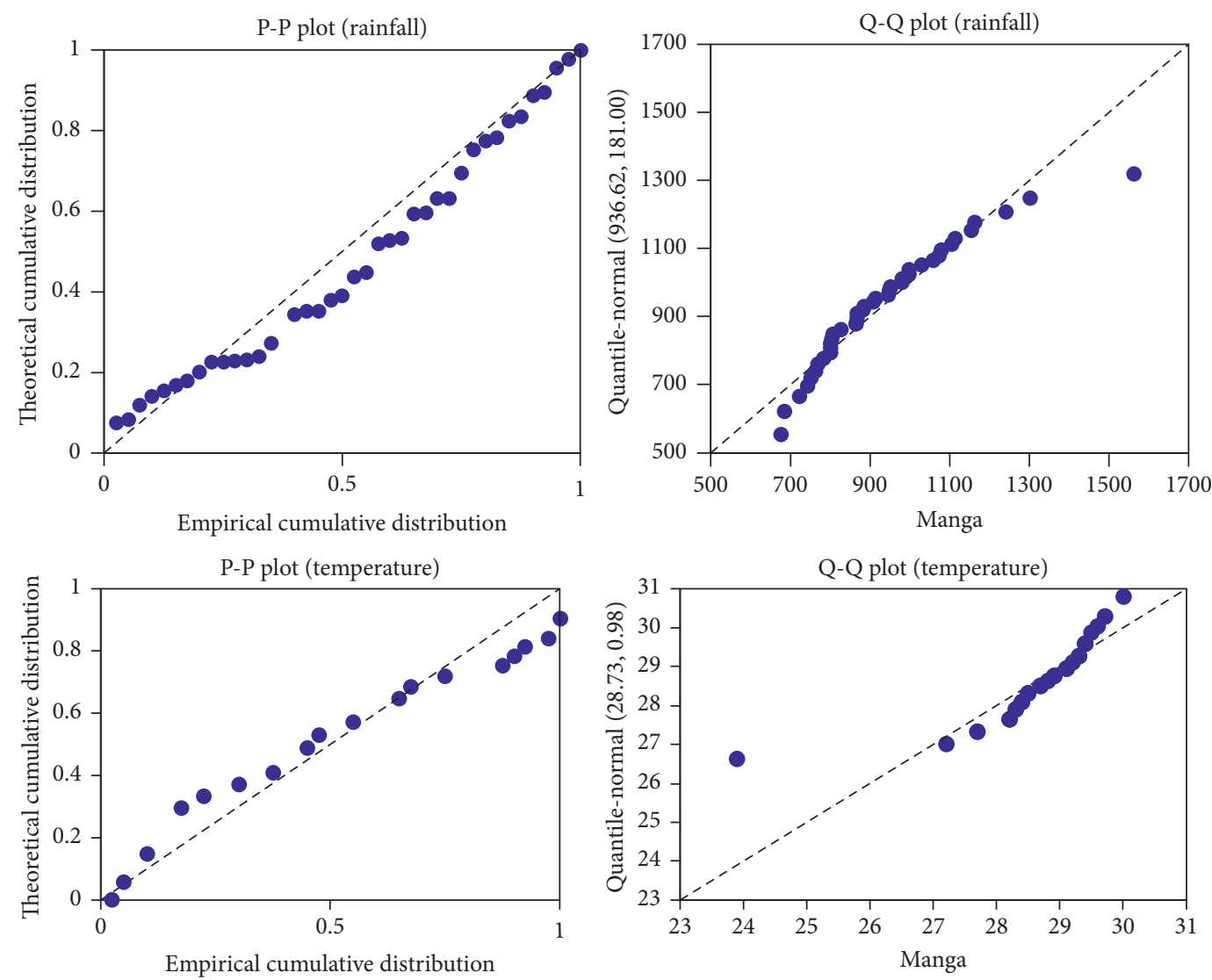

(c)

Figure 2: Visual inspection of P-P and Q-Q plots for rainfall and temperature. (a) Binduri gauge station. (b) Garu-Tempane gauge station. (c) Manga gauge station.

change point at Binduri and Garu-Tempane during 1987 in mean annual rainfall. However, all three tests had $P$ values $\geq 0.05$, hence meeting the assumption of homogeneity of rainfall data's suitability for trend testing and thus implying that at least majority of the datasets were found by the test to be of homogenous series and hence useful for the trend analysis irrespective of the change point. Figures 3(a)-3(c) show the graphical results of the homogeneity test analysis.

Table 4 shows statistical results of the homogeneity analysis for both rainfall and temperature and their comparative test statistics (Pettitt's test, SNHT, and Buishand's test). The table shows that, among the 40 years under study, only two (1988 and 1993) were found to be significantly inhomogeneous. In the mean temperature, however, significant change points were observed in 2010 for Binduri and Garu-Tempane and in 1992 for Manga. Both Pettitt's and Buishand's tests found a change point (T) in 1992 at Manga, while Buishand's test was met with a change point in 2010 at both Binduri and Garu-Tempane.

3.3. Seasonal Nature of Monthly Rainfall. In Figure 4, monthly rainfall patterns are observed to be similar in all three stations. It is shown in Figure 4 that there is virtually no rainfall in the period from December to February. The onset of rain in the area is March; rainfall amount begins to increase in April but becomes significant in May. Rain is highest in August and begins to reduce in volume from September to November. The period between May and September is the wet season and that from October to April is the dry season of the Bawku Area of Ghana. It is observed that there is a unimodal rainfall regime in the study area irrespective of the location of the gauge station.

3.4. Trends and Variability in Mean Annual Rainfall. A Mann-Kendall (MK) nonparametric test was used to test the trends available in the rainfall and temperature data whose results are presented in Tables 5 and 6 . The results are based on three separate meteorological stations. As a measure of the link between two subsequent annual rainfall and temperature datasets, the MK result is based on the computations of Kendall's tau with a null hypothesis $\left(\mathrm{H}_{0}\right)$ of no trend in the dataset. Positive and negative MK test results signify an increasing and decreasing trend in dataset, respectively. It is observed in Table 5 that annual rainfall amount at Manga station shows statistically significant positive $(P<0.05)$ trend; hence, the null hypothesis $\left(\mathrm{H}_{0}\right)$ is rejected at the Manga rainfall station. In the same Table 5, Sen's slope estimator depicts an upward trend for rainfall in all the stations: Binduri, Manga, and Garu-Tempane. It, therefore, implies that both Sen's slope and Mann-Kendall test are in 

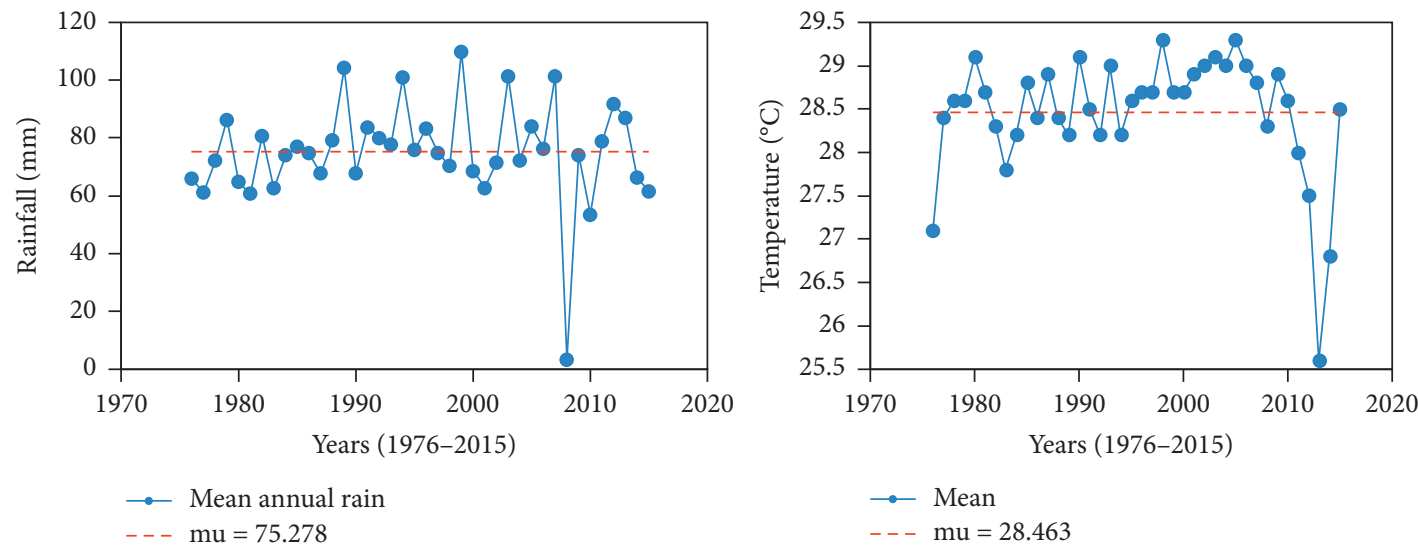

(a)
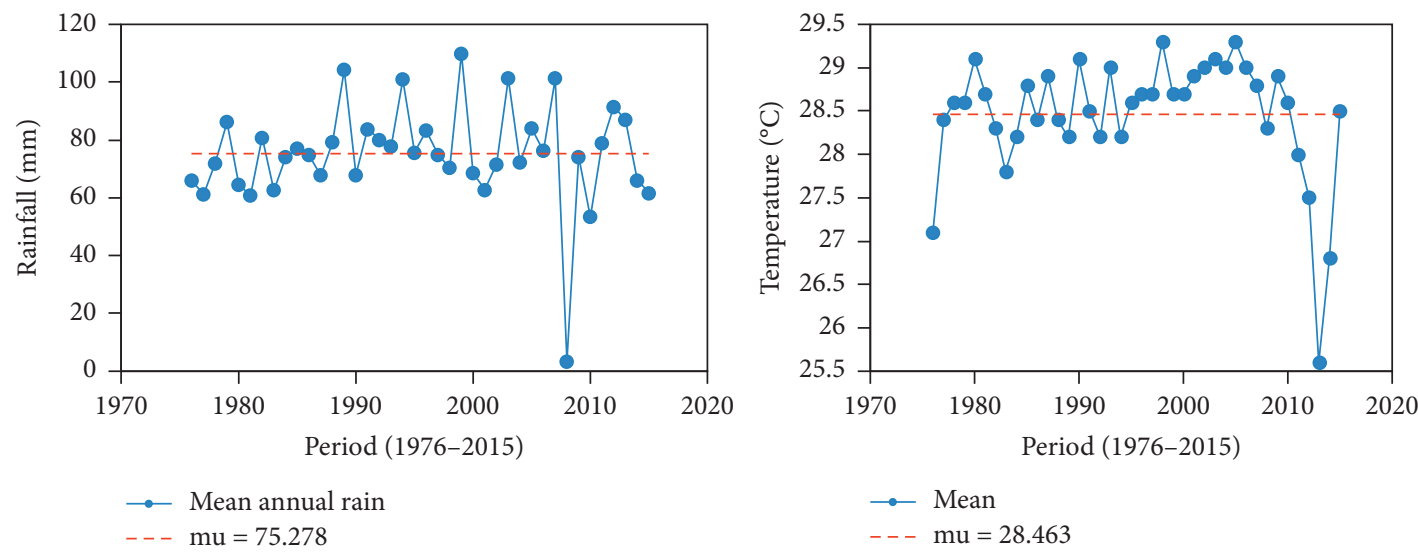

(b)
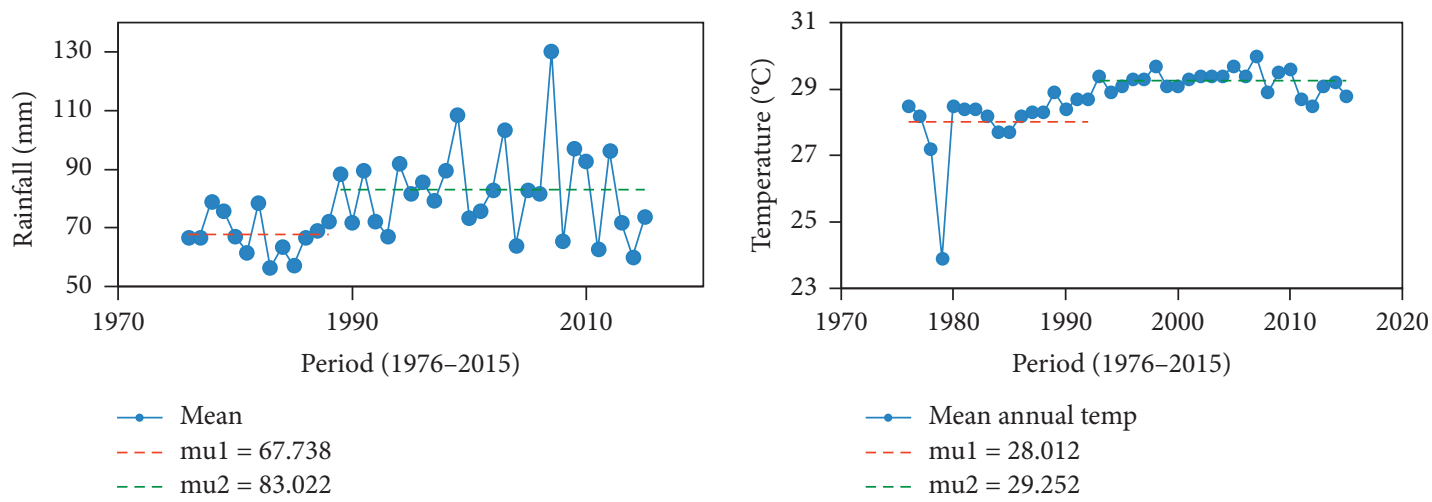

(c)

FIGURE 3: Homogeneity test showing change point T in annual rainfall and temperature. (a) Binduri gauge station. (b) Garu-Tempane gauge station. (c) Manga gauge station.

TABLE 4: Homogeneity test statistics.

\begin{tabular}{|c|c|c|c|c|c|c|}
\hline \multirow{2}{*}{ Meteorological station } & \multicolumn{2}{|c|}{ Pettitt's test } & \multicolumn{2}{|c|}{ SNHT test } & \multicolumn{2}{|c|}{ Buishand's test } \\
\hline & $\mathrm{T}$ & Sig. & $\mathrm{T}$ & Sig. & $\mathrm{T}$ & Sig. \\
\hline \multicolumn{7}{|l|}{ Rainfall } \\
\hline Binduri & 1987 & 0.628 & 2007 & 0.449 & 2007 & 0.447 \\
\hline Garu-Tempane & 1987 & 0.625 & 2007 & 0.471 & 2007 & 0.460 \\
\hline Manga & 1988 & $0.016^{*}$ & 1988 & 0.091 & 1993 & $0.017^{*}$ \\
\hline \multicolumn{7}{|l|}{ Temperature } \\
\hline Binduri & 2009 & 0.365 & 2011 & 0.052 & 2010 & $0.020^{*}$ \\
\hline Garu-Tempane & 2009 & 0.371 & 2011 & 0.052 & 2010 & $0.022^{*}$ \\
\hline Manga & 1992 & $\leq 0.001^{*}$ & 1998 & 0.053 & 1992 & $\leq 0.001^{*}$ \\
\hline
\end{tabular}

${ }^{*}$ Sig. at 0.05 . 


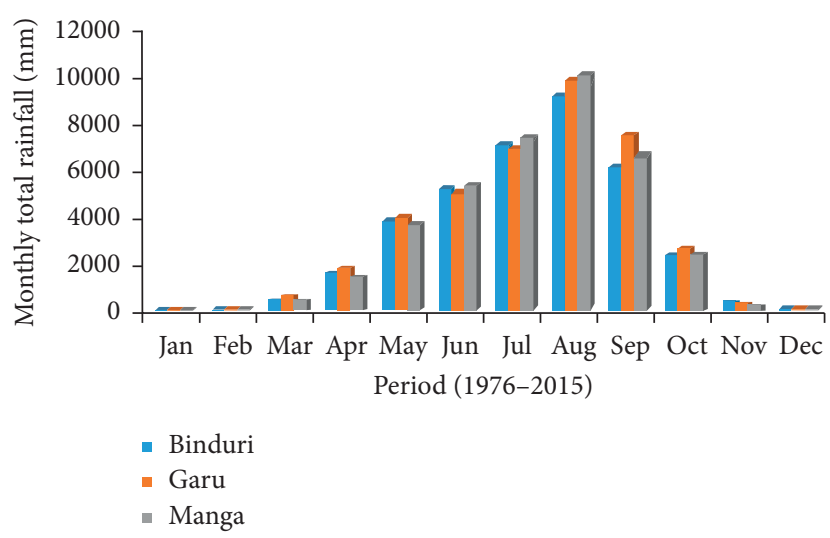

Figure 4: Rainfall monthly cycles in the Bawku Area.

TABLE 5: Mann-Kendall trend test for annual rainfall.

\begin{tabular}{lcccccccccc}
\hline Meteorological station & No. of years & MK stat. $(\mathrm{S})$ & K. tau & Min & Max & M & SD & $P$ value & CI [L-U] & Sen's slope \\
\hline Binduri & 40 & 72.0 & 0.092 & 3.5 & 109.9 & 75.3 & 17.5 & 0.408 & $-0.256-0.489$ & 0.152 \\
Garu-Tempane & 40 & 112.0 & 0.14 & 58.0 & 103.3 & 80.5 & 11.3 & 0.196 & $-0.112-0.527$ & 0.192 \\
Manga & 40 & 196.0 & 0.252 & 56.3 & 130.2 & 78.1 & 15.3 & $0.023^{*}$ & $0.056-0.882$ & 0.432 \\
Mean & 40 & 132.0 & 0.169 & 55.8 & 111.6 & 77.9 & 11.8 & 0.127 & $-0.079-0.545$ & 0.219 \\
\hline
\end{tabular}

${ }^{*}$ Sig. at 0.05 . ${ }^{*}$ Reject $\mathrm{H}_{0}$ at $\leq 0.05$ level or accept $\mathrm{H}_{1}$ at $\geq 0.05$.

TABLE 6: Mann-Kendall trend test for annual temperature.

\begin{tabular}{|c|c|c|c|c|c|c|c|c|c|c|}
\hline Meteorological station & No. of years & MK stat. (S) & K. tau & Min & Max & $\mathrm{M}$ & $\mathrm{SD}$ & $P$ value & $\mathrm{CI}[\mathrm{L}-\mathrm{U}]$ & Sen's slope \\
\hline \multicolumn{11}{|l|}{ Binduri } \\
\hline Mean & 40 & 41.0 & 0.054 & 25.6 & 29.3 & 28.5 & 0.7 & 0.640 & $0.000-0.006$ & 0.001 \\
\hline $\operatorname{Max} T$ & 40 & 195.0 & 0.264 & 34.5 & 36.0 & 35.3 & 0.4 & $0.022^{*}$ & $0.010-0.014$ & 0.012 \\
\hline $\operatorname{Min} \mathrm{T}$ & 40 & -29.0 & -0.038 & 16.3 & 22.8 & 21.7 & 1.3 & 0.743 & $-0.007-0.000$ & 0.000 \\
\hline \multicolumn{11}{|l|}{ Garu-Tempane } \\
\hline Mean & 40 & 384.0 & 0.503 & 27.6 & 32.9 & 28.9 & 0.9 & $0.0001^{*}$ & $0.028-0.050$ & 0.033 \\
\hline $\operatorname{Max} T$ & 40 & 484.0 & 0.634 & 32.8 & 36.1 & 34.9 & 0.8 & $0.0001^{*}$ & $0.048-0.053$ & 0.050 \\
\hline Min $\mathrm{T}$ & 40 & 269.0 & 0.352 & 19.6 & 30.2 & 22.8 & 1.4 & $0.002^{*}$ & $0.026-0.033$ & 0.030 \\
\hline \multicolumn{11}{|l|}{ Manga } \\
\hline Mean & 40 & 403.0 & 0.529 & 23.9 & 30.0 & 28.7 & 0.9 & $0.0001^{*}$ & $0.038-0.044$ & 0.041 \\
\hline $\operatorname{Max} \mathrm{T}$ & 40 & 329.0 & 0.432 & 34.6 & 36.9 & 35.6 & 0.6 & $\leq 0.001^{*}$ & $0.030-0.037$ & 0.033 \\
\hline Min $\mathrm{T}$ & 40 & 352.0 & 0.458 & 12.9 & 23.2 & 21.9 & 1.7 & $0.0001^{*}$ & $0.042-0.050$ & 0.046 \\
\hline
\end{tabular}

${ }^{*}$ Sig. at 0.05 . ${ }^{*}$ Reject $\mathrm{H}_{0}$ at $\leq 0.05$ level or accept $\mathrm{H}_{1}$ at $\geq 0.05$.

tandem to the increasing trend of rainfall at Manga and Garu-Tempane.

Graphically, a linear regression trend line was further used to show evidence of the rainfall variability and trend in the dataset. As shown in Figure 5, whereas Binduri showed a slightly declining trend (negative trend line) of total annual rainfall, both Manga and Garu-Tempane showed an upward trend (positive trend line). However, it is observed that, in all the three meteorological stations in the study area, rainfall is erratic and varies with time over the 40-year period.

Again, it is illustrated in Figure 5 that, in all the three meteorological stations, rainfall amount is highly concentrated between $600 \mathrm{~mm}$ and $1000 \mathrm{~mm}$ annually. The extremely high $(1562.7 \mathrm{~mm})$ amount of rainfall recorded in all the three stations occurred in 2007 at Manga meteorological station and the extremely low $(42.3 \mathrm{~mm})$ amount was recorded in Binduri in 2008. Total annual rainfall change was computed on the fitted regression line to show the changes in annual rainfall of each rainfall station. The results are $-0.029,2.724$, and $5.4613 \mathrm{~mm} /$ year in Binduri, Garu-Tempane, and Manga, respectively.

3.5. Annual Rainfall Anomalies. The Standardised Precipitation Index (SPI) was used to generate and describe the anomalies of total annual rainfall (three stations combined) in the study area over the 40 -year study period. The aim was to identify years that witnessed more wetness or dryness over the period in the study area. As such, the authors combined the data of the three stations to arrive at a common mean that would then be used to generalize for the area. Thus, an average of the three stations was calculated 


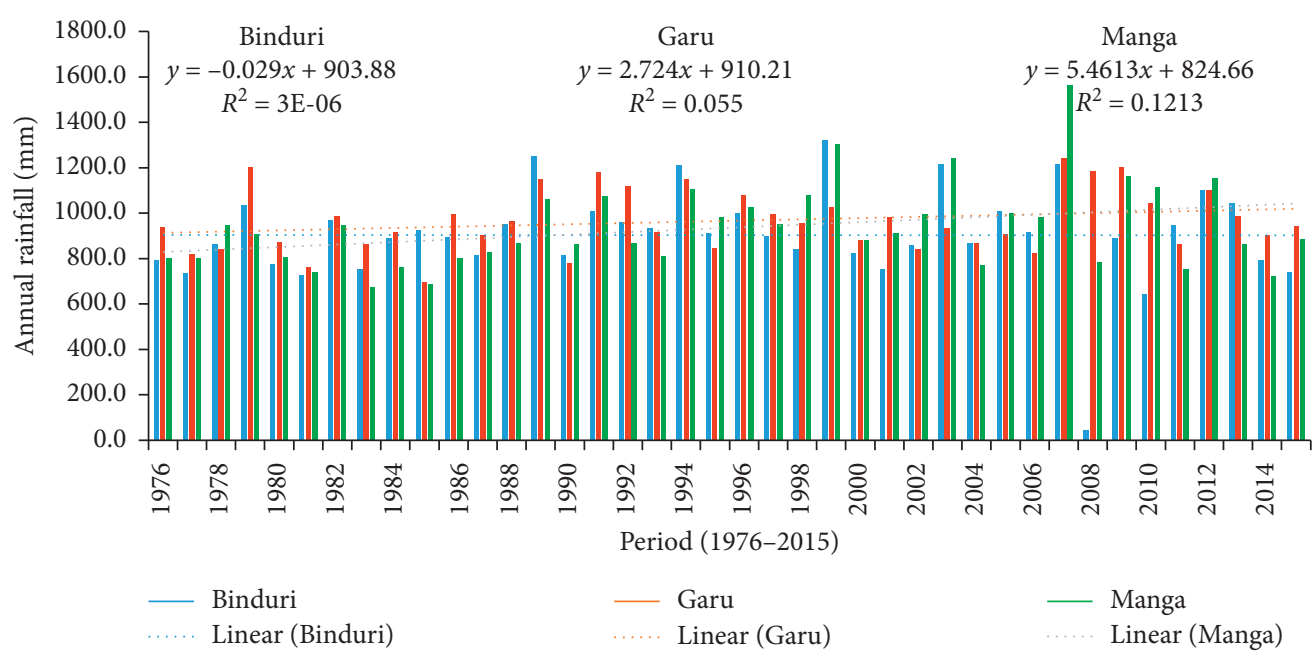

Figure 5: Long-term variability in annual total rainfall.

and subsequently used to generate the SPI. Results of SPIs are either positive (wet) or negative (dry), with positive values implying a greater $(>)$ than median precipitation and negative values indicating less $(<)$ than median precipitation. Of course, this was necessary because of the role rainfall plays in the livelihoods of the residents of this part of the Savannah agroclimatological zone in Ghana. It is important to note that the SPI can be generated over different timescales; however, in this study, to reflect a long-term precipitation pattern, a 12month timescale SPI was adopted to compare the rainfall pattern for 12 consecutive months of the first year with 12 consecutive months of all other years.

An SPI result with positive (+) value indicates wetness, while negative $(-)$ value implies dryness, but the intensity is dependent on the value of SPI. It is observed from Figure 6 that it is only in 2006 that the SPI was $\geq 2.0$ to imply an extremely wet year among the years under study with $2.3 \%$ probability of recurring once every 50 years. In the years 1993 and 1998, SPI values were $\geq 1.5$ and $\leq 1.99$, respectively. This implies very wet years with $4.4 \%$ likelihood to recur once every 20 years. Also, in 1988-1991, 1994, 1996, 1997, 1999, 2001-2004, 2008, 2009, 2011, 2012, and 2014, the SPI values were $\geq 0.0$ and $\leq 0.99$, which suggest mild wetness. They are $34.1 \%$ likely to recur once in every 3 years.

Conversely, years 1977-1979, 1981-1982, 1985-1987, 1992, $1995,2000,2005$, and 2010 have their SPI values $\geq 0.0$ and $\leq$ -0.99 , implying mild dryness with $34.1 \%$ likelihood of recurrence once every 3 years. During 1984, 1985, and 2014 SPI values were $\geq-1$ and $\leq-1.49$, denoting moderate dryness with $9.2 \%$ recurrence probability once in 10 years. Lastly, 1976, 1980, and 2007 recorded SPI values of $\geq-1.5$ and $\leq-1.99$ to suggest very dry years with $4.4 \%$ likelihood of recurrence once in 20 years.

However, based on the baseline period, the overall observation shows that the longest dry period occurred from 1976 to 1987, marked by negative anomalies, whereas 1988-1991 and 1996-1999 were the longest wet periods observed. Meanwhile, the period after 1987 witnessed more excess rainfall than shortages.
3.6. Seasonal Nature of Monthly Temperature. In Ghana, Temperature is uniformly high throughout the year; however, there are fluctuations at the regional and local levels. The three gauge stations do not show significant graphical discrepancies in pattern. Overall, temperature ranges between $26.4^{\circ} \mathrm{C}$ and $33.3^{\circ} \mathrm{C}$ from January to December as observed in Figure 7. There are two recognizable peaks of temperature: March-April and October-November. Temperature is highest during March and April with highest monthly temperature recorded in April. August, meanwhile, is the month with the lowest temperature throughout the year, coinciding with the month with the highest rainfall. Specifically, temperature is observed to be relatively higher and lower at Garu-Tempane and Binduri gauge stations, respectively, than all other stations as observed from the graph. Wet season's temperature is relatively low $\left(25-27^{\circ} \mathrm{C}\right)$ between July and September, while dry season's temperature is relatively higher $\left(27-32^{\circ} \mathrm{C}\right)$ from February to April (Figure 7).

3.7. Trend and Variability in Mean Annual Temperature. Table 6 shows the MK trend test results for mean temperature of the three stations. It is observed that, at Binduri gauge station, only the minimum temperature of the area showed a decreasing trend, implying that, on average, minimum temperature of the area has declined over the years. On the contrary, the maximum temperature of Binduri station showed a positive and significant trend. The null hypothesis $\left(\mathrm{H}_{0}\right)$ of the mean and minimum temperature is hence accepted as $\mathrm{H}_{1}$ is rejected.

Furthermore, it is observed that, at a $P$ value of 0.05 , minimum, maximum, and mean temperatures of the GaruTempane and Manga stations have positive trend. Thus, the null hypothesis $\left(\mathrm{H}_{0}\right)$ is rejected at these gauge stations. That is, given the 40-year period, Garu and Manga have witnessed rising temperatures on average. In Table 6, Sen's slope estimator shows a positive trend for all temperature datasets in 


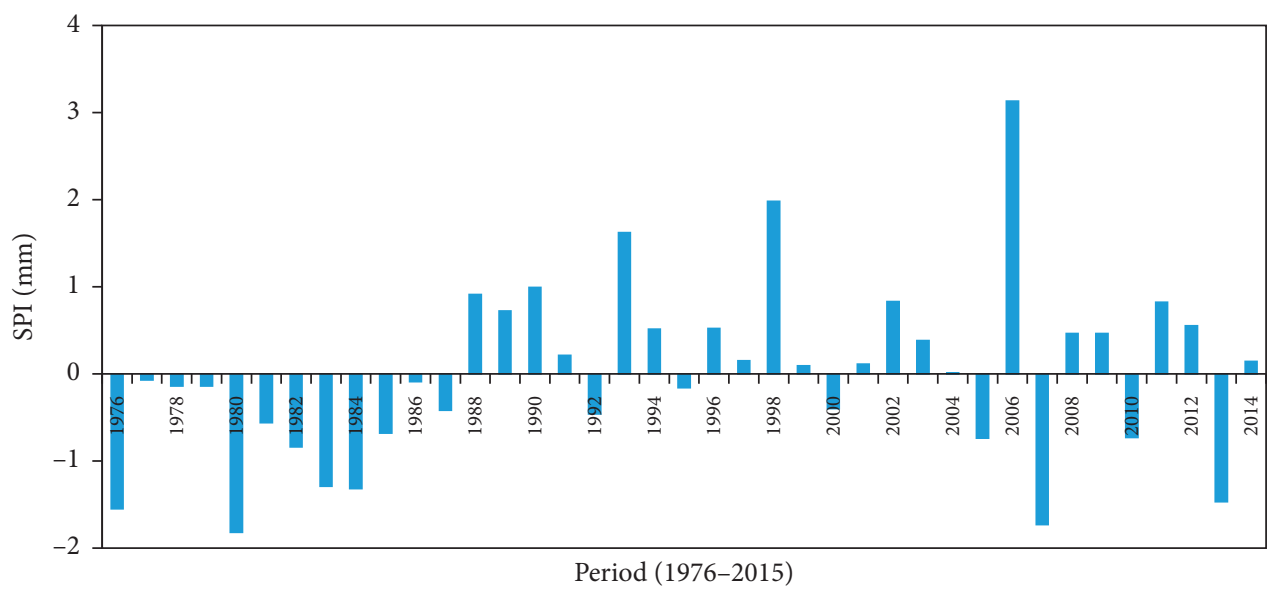

FIgURE 6: Annual rainfall anomalies.

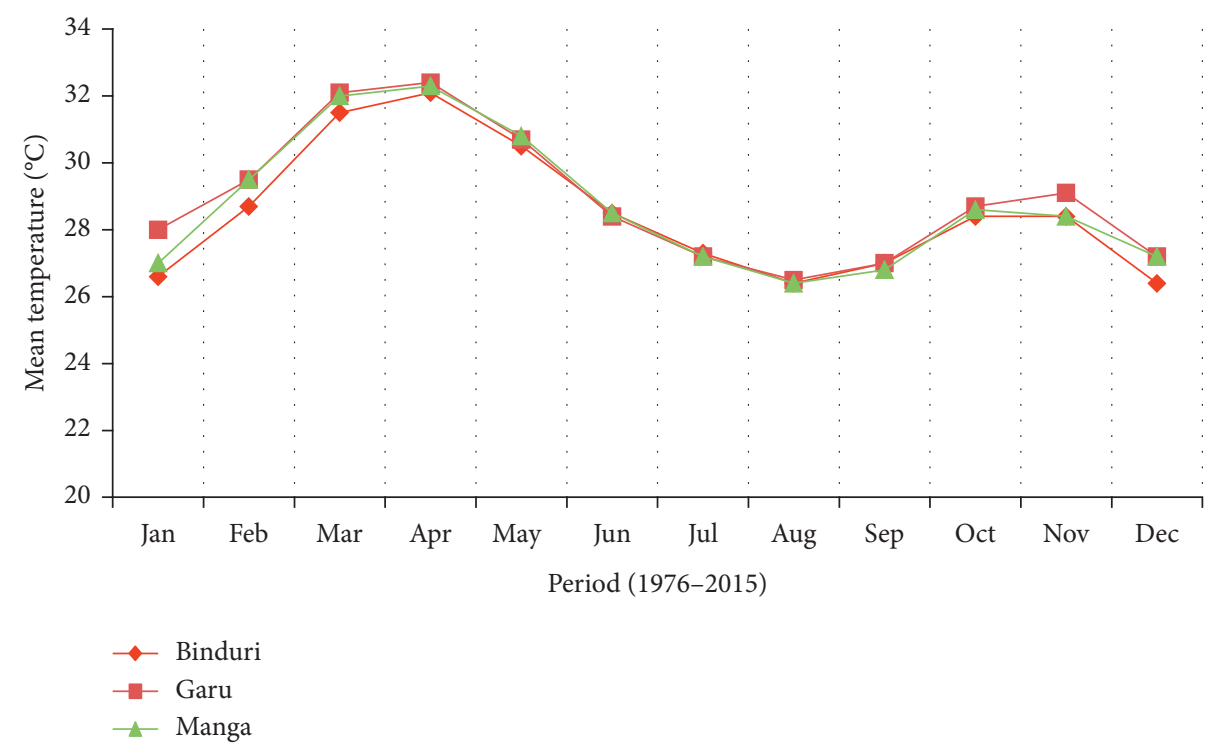

Figure 7: Monthly cycle of temperature.

the meteorological stations. Thus, the Mann-Kendall trend test and Sen's slope estimator are in agreement.

Likewise, Figure 8 shows the graphical representation of the mean annual temperature over the three stations. A linear regression trend line was fitted in the graph to show the variation of temperature over the study period. It is observed from Figure 8 that temperature is uniformly high in all the three stations with minor extreme cases. On a whole, the highest $\left(32.9^{\circ} \mathrm{C}\right)$ mean recorded temperature of the three stations was in 1998 in Garu-Tempane, while the lowest $\left(23.9^{\circ} \mathrm{C}\right)$ was recorded in 1979 at Manga meteorological station.

With an R-square of $34.7 \%$, the rise in temperature in Manga was the most significant, with just about $14 \%$ in Garu-Tempane. Binduri, on the other hand, shows a declining mean temperature over the period. Regardless of the above, the mean temperature of the areas witnessed a steady rise. Also, Figure 8 depicts an average temperature change based on meteorological station with a mean annual temperature change, ranging from Binduri to Manga, of $-0.0085^{\circ} \mathrm{C}$ to $0.05^{\circ} \mathrm{C} /$ year $(0.9 \%-5 \%)$ at $95 \%$ confidence level.
3.8. Temperature Anomalies. Temperature has a profound impact on the hydrological cycle of the Savannah agroclimatological zone and hence the general water security in the area due to its impact on evapotranspiration rate. As such, finding the temperature anomalies over the period is prudent as results could influence future agricultural plans in the area. Temperature anomaly measures the discrepancy of the observed data from the average of the dataset. Whereas positive $(+)$ values imply that the 40 -year average temperature is smaller than the observed, a negative $(-)$ value implies a large observed value.

Figure 9 generally shows that many of the years in perspective witnessed a positive $(+)$ value in temperature with the anomalies ranging between -1.42 and $1.2^{\circ} \mathrm{C}$. Figure 9 also shows that, among the years with annual rising trend in temperature anomalies, 1988 recorded the extreme $\left(1.2^{\circ} \mathrm{C}\right)$, suggesting a hot condition. This was followed by years 1998, 2001-2007, and 2009-2010 with values $\geq 0.5$ and $<1.0$, implying warmer conditions than the average. The rest (1990, 1993, 1995-1997, 1999-2000, and 2011) were $\geq 0.0$ and 


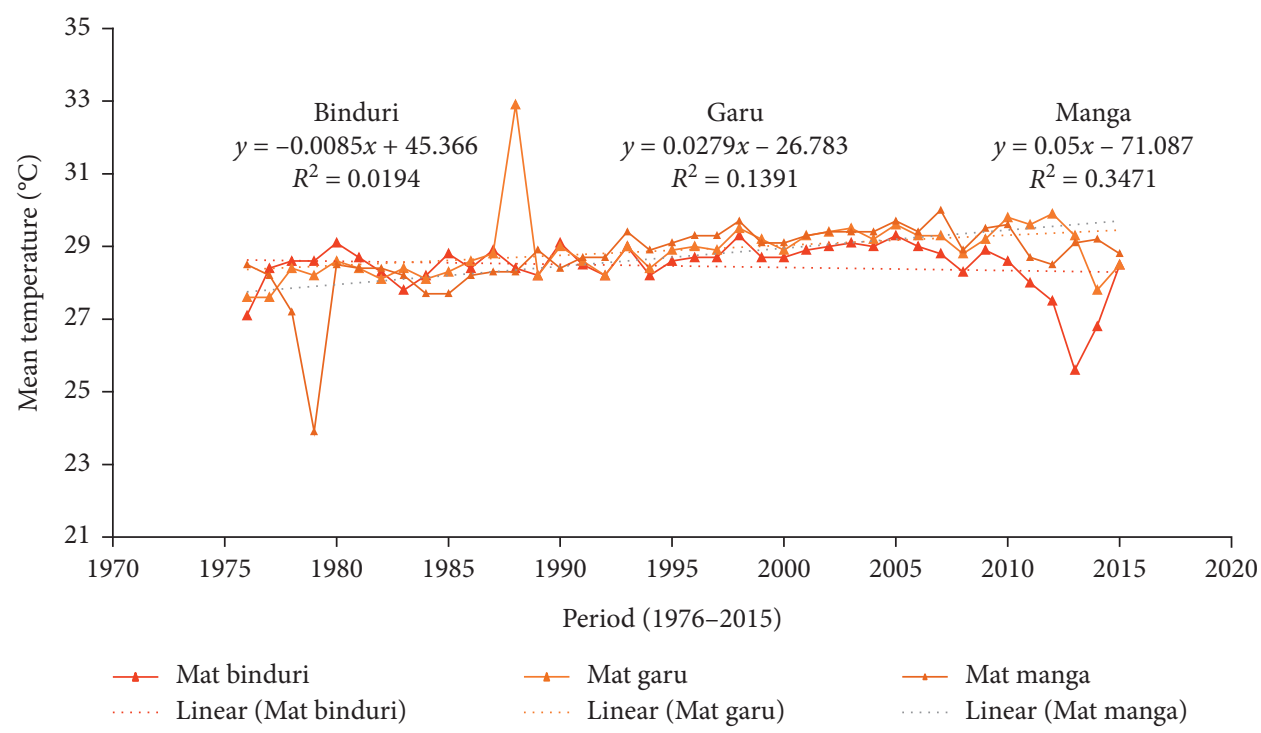

Figure 8: Long-term variability of mean annual temperature.

$<0.5$. The above temperature difference indicates a nearnormal temperature condition, while 1980, 1987, and 2008 witnessed no change (zero change) in temperature in relation to the average value, hence a normal temperature.

In contrast, Figure 9 further shows that $1979\left(-1.8^{\circ} \mathrm{C}\right)$ and $1976\left(-1.0^{\circ} \mathrm{C}\right)$ recorded the lowest temperature anomaly with values $\leq-1^{\circ} \mathrm{C}$, indicating years with the coolest temperature in comparison with the average of the area. A cooler condition in comparison to the average temperature of the area was experienced in the years 1977-1978, 1983-1984, 2013, and 2014 with recorded values $\leq-0.5$ and $>-1.0$. Lastly, near-normal conditions were observed in the years 1982, 1986, 1989, 1991-1992, 1994,2012 , and 2015 with the anomaly $\leq-0.5$.

3.9. One-Way Post Hoc ANOVA. A one-way post hoc ANOVA was conducted to explore the differences in means of decadal rainfall and temperature measured in millimetres $(\mathrm{mm})$ and degree Celsius $\left({ }^{\circ} \mathrm{C}\right)$, respectively. The years were divided into four decades (10 years) from the year in which recording began as far as this research is concerned (Group 1: 1976-1985, Group 2: 1986-1995, Group 3: 1996-2005, and Group 4; 2006-2015). This analysis was done separately for the three meteorological stations and the result is presented in Tables 7-9. In ANOVA, test of homogeneity of variance uses Levene's test, which tests whether the variance in scores is the same for each group. If the $P$ value (sig.) is greater than 0.05 (i.e., $P>0.05)$, it means the homogeneity assumption is not violated and hence one can go on to interpret the post hoc ANOVA results. However, if the test results violate the homogeneity assumption (i.e., if $P<0.05$ ), then you consult the robust tests of equality of means and hence use the Welch and Brown-Forsythe ANOVA to interpret your output. But since homogeneity of variance was not violated in this analysis, Levene's test was used for the interpretation.
3.9.1. Binduri Meteorological Station. The ANOVA results in Table 7 show no statistically significant differences in the year groups with respect to rainfall. However, there was a statistically significant difference in the groups at the $P<0.05$ level in temperature for the four groups: $F(3,476)=$ 3.623; $P=0.013$. Despite reaching statistical significance, the actual difference in mean scores between the groups was quite small. The effect size, calculated using eta-squared, was .02. Post hoc comparisons using the Tukey HSD test indicated that the mean score for Group $3(M=28.93, \mathrm{SD}=2.15)$ was significantly different from Group $4 \quad(M=28.02$, $\mathrm{SD}=2.25)$. There was, however, no significant difference between Group $3(M=28.93, \mathrm{SD}=2.15)$ and Group 1 or Group 2. Again, there was no significant difference in means between Group $1(M=28.35, \mathrm{SD}=2.23)$ and Group 2 or Group 4; and there was no significant difference in means between Group $2(M=28.35, \mathrm{SD}=2.19)$ and Group 4 .

3.9.2. Garu-Tempane Meteorological Station. The result in Table 8 shows that there were no significant differences in means of the year groups with respect to rainfall, but temperature showed evidence of statistically significant differences in the means of the year groups at the $P<0.05$ level for the four year groups: $F(3,476)=3.158 ; P=0.025$.

Notwithstanding the level of significance, the actual difference in mean scores between the groups was low. As such, the effect size was calculated using eta square and the result was .02. Meanwhile, in the post hoc comparisons using the Tukey HSD test, it was found that there was a significant difference in the mean scores of Group $1 \quad(M=28.17$, $\mathrm{SD}=2.17)$ and Group $3(M=29.25, \mathrm{SD}=2.12)$ and that there were no significant differences between any other groups.

3.9.3. Manga Meteorological Station. The result in Table 9 shows that there were no significant differences in means of the year groups with respect to rainfall but there was significant difference in means of temperature at $P<0.05$ level 


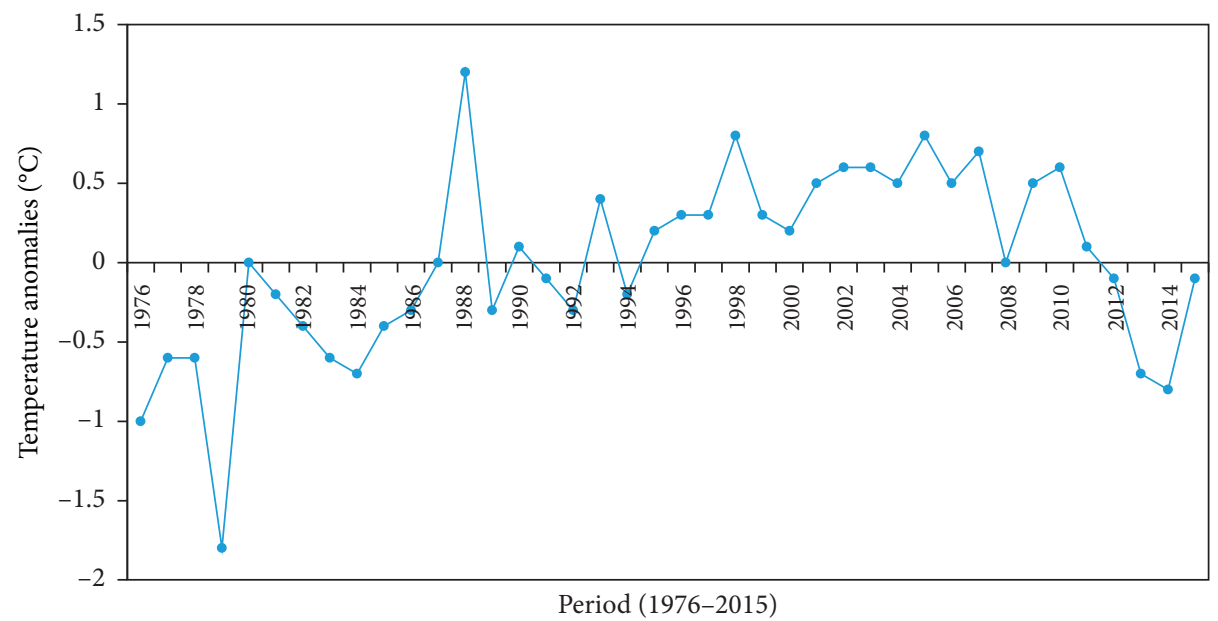

FIgURE 9: Mean annual temperature anomalies.

for the year groups: $F(3,476)=12.821 ; P<0.001$. The actual difference in mean temperature values was moderate evidence from the effect size of 0.07 calculated using etasquared. Post hoc multiple comparisons using the Tukey HSD test further indicated that the mean score for Group 1 $(M=27.66, \quad \mathrm{SD}=2.78)$ was significantly different from Group $2(M=28.71, \quad \mathrm{SD}=2.16)$, Group $3 \quad(M=29.36$, $\mathrm{SD}=2.16)$, and Group $4(M=29.16, \mathrm{SD}=2.11)$. Group 2 $(M=28.71, \mathrm{SD}=2.16)$ did not differ significantly from either Group 3 or Group 4; Group $3(M=29.36, \mathrm{SD}=2.16)$ did not differ significantly from Group 4.

\section{Discussion}

In this study, emphasis was placed on the temporal description of temperature and rainfall in the Bawku Area of Upper East Region of the Savannah zone of Ghana. Similar to other studies, interannual and high values of changes in rainfall over the study area are in agreement with [15-17], and therefore it is implied that residents will still be in a state of uncertainty in relation to rainfall in the coming years. This is because of the difficulty in forecasting rainfall in an area with erratic and varied rainfall pattern. Rainfall variability in the study area is also consistent with the findings of $[45,46]$. Thus, the fluctuations in the rainfall distribution on annual basis are not uncommon in the Savannah zone. However, this finding is in sharp contrast with $[16,45]$, in which rainfall on the whole was found to be decreasing in the northern part in general and Upper East Region of the country. This could probably be as a result of the fact that their study period was longer and dated back (1954-2010 and 1961-2007, respectively) to an earlier time than the current one and also because it is a wider area in comparison to the current study area. Thus, this study established that all the three meteorological stations on average enjoyed a slight increase in rainfall distribution.

Having an increasing rainfall trend is quite a welcoming result for the residents in the area because of its potential agricultural, hydrological, and socioeconomic effects in an area that is highly populated by farmers, rain-fed agriculturalist for that matter. The increasing rainfall in the area supports the findings of [46] that found that, in the Savannah zone of Ghana, many of the years between 1901 and 2010 experienced above-normal rainfall in the area. Given that there is an upward trend in rainfall, farmers and the residents in general will be relieved especially in relation to water management towards future use. This is because whereas crop farmers need water for their plants, those in animal husbandry equally rely on water for their animals. Indeed, the domestic use of water cannot be underestimated. However, an increasing number of rainfall-deficient years as shown by the anomalies are an indication of drought in those years. This even worsens the rainfall uncertainty situation in the area and rather calls for planning because of the significant role rainfall plays in the lives of the residents in the area.

The fact that there is little or no rainfall from November to March suggests the significance of the dry season in this part of the country. In the savannah areas of Africa, reports of high temperature and low rainfall have been established as a consequent of the tropical continental air mass [47]. The seasonal nature of the monthly rainfall in the area is impacted upon by the dominance of the dry tropical continental air mass and the moist tropical maritime air mass from which we have the North East Trade Winds (harmattan) and South West Monsoon Winds, respectively. Even though these are the major determinants of the rainfall seasons in Ghana $[26,48]$, it is important to note that the harmattan dominates the Savannah area of Ghana against the influence of the monsoon, hence leading to the long dry period with little amount of rainfall experienced. As such, months of negligible rainfall amount in the study area are generally due to the influence of North East Trade Winds, which are dry and cold in nature. This is not surprising especially in relation to the SPI results witnessing more dryness than wetness. The effect of this air mass on rainfall is similar to temperature distribution over the area. Thus, the wind circulation in West Africa is dominated by the North East Trade Winds, which originate from the dry and hot Sahara 
Table 7: ANOVA test statistics, Binduri.

\begin{tabular}{|c|c|c|c|c|c|c|}
\hline Binduri & SS & $\mathrm{df}$ & MS & $\mathrm{F}$ & Sig. & Eta square \\
\hline \multicolumn{7}{|l|}{ Rainfall } \\
\hline Between groups & 13620.562 & 3 & 4540.18 & 0.570 & 0.635 & 0.0035 \\
\hline Within groups & 3794549.32 & 476 & 7971.74 & & & \\
\hline Total & 3808169.88 & 479 & & & & \\
\hline \multicolumn{7}{|l|}{ Temperature } \\
\hline Between groups & 52.980 & 3 & 17.660 & 3.623 & 0.013 & 0.0223 \\
\hline Within groups & 2320.352 & 476 & 4.875 & & & \\
\hline Total & 2373.332 & 479 & & & & \\
\hline
\end{tabular}

${ }^{*}$ Sig at 0.05 level.

TABle 8: ANOVA test statistics, Garu-Tempane.

\begin{tabular}{|c|c|c|c|c|c|c|}
\hline Garu-Tempane & SS & $\mathrm{df}$ & MS & $\mathrm{F}$ & Sig. & Eta square \\
\hline \multicolumn{7}{|c|}{ Rainfall: Garu-Tempane } \\
\hline Between groups & 9451.697 & 3 & 3150.57 & 0.380 & 0.768 & 0.002 \\
\hline Within groups & 3947291.13 & 476 & 8292.63 & & & \\
\hline Total & 3956742.83 & 479 & & & & \\
\hline \multicolumn{7}{|c|}{ Temperature: Garu-Tempane } \\
\hline Between groups & 88.512 & 3 & 29.504 & 3.158 & 0.025 & 0.019 \\
\hline Within groups & 4446.946 & 476 & 9.342 & & & \\
\hline Total & 4535.461 & 479 & & & & \\
\hline
\end{tabular}

${ }^{*}$ Sig at 0.05 level.

TABle 9: ANOVA test statistics, Manga.

\begin{tabular}{|c|c|c|c|c|c|c|}
\hline Manga & SS & $\mathrm{df}$ & MS & $\mathrm{F}$ & Sig. & Eta square \\
\hline \multicolumn{7}{|l|}{ Rainfall } \\
\hline Between groups & 30578.238 & 3 & 10192.75 & 1.111 & 0.344 & 0.007 \\
\hline Within groups & 4367338.58 & 476 & 9175.081 & & & \\
\hline Total & 4397916.82 & 479 & & & & \\
\hline \multicolumn{7}{|l|}{ Temperature } \\
\hline Between groups & 206.743 & 3 & 68.914 & 12.82 & $\leq 0.001^{*}$ & 0.075 \\
\hline Within groups & 2558.597 & 476 & 5.375 & & & \\
\hline Total & 2765.340 & 479 & & & & \\
\hline
\end{tabular}

${ }^{*}$ Sig at 0.05 level.

Desert; this dry and dusty wind has tremendous effect on rainfall and temperature of the study area. That is not to say, however, that factors including absence of vegetation cover and absence of river and water bodies have no effects on the local atmospheric circulation in the area. However, the Savannah areas of Northern Ghana have relatively gentle slopes with rare vegetation and hence we speculate less effect of orography in the area.

On the contrary, this study also establishes that temperature assumes a uniformly increasing trend in the study area but varies yearly across the stations, which conforms to global and international studies about variations in temperature $[2,49]$. It is further in consistence with the findings of $[16,20,50,51]$ that differently found increasing trends in annual, seasonal, and decadal day and night temperatures in the northern regions of Ghana. The increasing temperature over the area carries with it some consequences in the livelihoods of the residents in terms of drought, dry spells, water shortage, and the possibility of conflict over water resources in the area. Thus, the fact that temperature is rising significantly implies that the rising temperature has the potential to nullify the rainfall figures through evapotranspiration. The consequence is the scarcity of water in the area as observed in the drying-up of rivers, wells, dams, and dugouts and soil moisture deficiency in the area. This is a major blow to farming in the area because of farmers' dependence on rain-fed farming. But it is an undeniable fact that the rising temperature in the area is partly attributed to anthropogenic activities through deforestation for charcoal production, clearing of vegetation for farming, population pressure on the environment, urbanisation, and urban heating [52].

Meanwhile, there are decadal differences in temperature groupings over the area. Whereas at the Binduri station there was an observed difference in temperature during 1996-2005 and 2006-2015, there was a difference in temperature during 1976-1985 and 1996-2005 in Garu-Tempane. Lastly, differences exist between 1976-1985 and 1986-1995, 1976-1985 and 1996-2005, and 1976-1985 and 2006-2015 at Manga meteorological station. This implies that, during the study period, temperature of the studied meteorological stations has rarely been constant over the 
decades. Thus, the effects of temperature variations felt by the residents have not been the same across the 40 years.

\section{Conclusion}

This study has proven to be an addition to the earlier studies regarding climate variability in the country, especially that of the Savannah agroclimatological zone. It is evident that in the study area rainfall is averagely low, with erratic pattern. It also fluctuates and varies in time with some extremely low and high periods of rainfall. Monthly cycles of rainfall and temperature show peaks in August and April, respectively. There were more years with negative mean annual rainfall anomalies than positives with severe long drought period prior to 1988. The temperature, on the other hand, was uniformly high in the study area with minor extreme cases, yet the anomalies indicate rising values of temperatures. The study is able to establish an upward rise in temperature over the study period among the three stations. Despite the insignificant differences in the interdecadal rainfall amount, temperature witnessed interdecadal variations over the years under study. In relation to the results, all stakeholders, including nongovernmental organisations and government, are recommended to ensure adequate provision of water supply through the construction of dam's wells and boreholes. These efforts will not just reduce water insecurity but will also increase the availability of resources for agricultural activities all-year-round since farmers will be able to farm even in dry seasons.

\section{Data Availability}

The data used to support the findings of this study are available from the corresponding author upon request.

\section{Conflicts of Interest}

The authors declare no conflicts of interest.

\section{Authors' Contributions}

Both authors contributed substantially and equally towards the success of this study, proofread the final manuscript, and approved it for publication.

\section{Acknowledgments}

The authors are very grateful to Dr. Osman Adams of the Department of Geography and Regional Planning, University of Cape Coast, Ghana, and to Professors Kwabena Barima Antwi and Simon Mariwah of the same department. The authors appreciate their wonderful mentoring and suggestions. The authors are also very grateful to $\mathrm{Mr}$. Richard Adade of Fisheries Department. The authors acknowledge the Ghana Meteorological Agency, Accra, for the provision of the climate data.

\section{References}

[1] F. Stolberg, O. Borysova, I. Mitrofanov, V. Barannik, and P. Eghtesadi, "Caspian sea. GIWA regional assessment
23, Global International Water Assessment (GIWA) 2003," 2003, https://www.giwa.net/areas/reports/r23/giwa_regional_ assessment_23.pdf.

[2] Intergovernmental Panel on Climate Change (IPCC), Climate Change 2007: Impacts, Adaptation and Vulnerability: Contribution of Working Group II to Fourth Assessment Report of the Intergovernmental Panel on Climate Change, M. L. Parry, O. F. Canziani, J. P. Palutikof, P. J. van der Linden, and C. E. Hanson, Eds., p. 976, Cambridge University Press, Cambridge, UK, 2008, http://www.cambridge.org/9780521880107.

[3] P. V. V. R. Prasada and S. L. Addisu, "Trend analysis and adaptation strategies of climate change in north central Ethiopia," International Journal of Agricultural Science and Research, vol. 3, no. 1, pp. 253-262, 2013, https://www.academia. edu/3407133/TREND_ANALYSIS_AND_ADAPTATION_ STRATEGIES_OF_CLIMATE_CHANGE_IN_NORTH_ CENTRAL_ETHIOPI.

[4] A. Longobardi and P. Villani, "Trend analysis of annual and seasonal rainfall time series in the Mediterranean area," International Journal of Climatology, vol. 30, no. 10, pp. 15381546, 2009.

[5] United State Environmental Protection Agency, Ghana Government Submission to the United Nations Framework Convention on Climate Change Ghana First Biennial Update Report, Ministry of Environment, Science, Technology and Innovation, Accra, Ghana, 2015.

[6] K. K. Azeez, M. M. Abnory, I. H. Sirikyi, and M. Adanusa, "Climate change and health management in the Central Region, Ghana," in Climate Change and Sustainable Development in Africa, Proceedings' of Second University of Cape Coast and University of Ilorin Joint International Conference, Illorin Press, Illorin, Nigeria, 2012.

[7] Intergovernmental Panel on Climate Change (IPCC), Climate Change 2014: Synthesis Report. Contribution of Working Groups I, II, III to the Fifth Assessment Report of the Intergovernmental Panel on Climate Change, Core Writing Team, R. K. Pachauri, and L. A. Meyer, Eds., p. 151, IPCC, Geneva, Switzerland, 2014, https://www.ipcc.ch/site/assets/uploads/2018/ 05/SYR_AR5_FINAL_full_wcover.pdf.

[8] A. S. Wijaya, "Climate change, global warming and global inequity in developed and developing countries (Analytical perspective, Issue, Problem and Solution)," IOP Conference Series: Earth and Environmental Science, vol. 19, p. 2014, Article ID 012008, 2014.

[9] Intergovernmental Panel on Climate Change (IPCC), Climate Change 2013: The Physical Science Basis. Contribution of Working Group I to Fifth Assessment Report of the Intergovernmental Panel on Climate Change, T. F. Stocker, D. Qin, G.-K. Plattner et al., Eds., p. 1535, Cambridge University Press, Cambridge, United Kingdom and New York, NY, USA, 2013.

[10] B. Hayelom, Y. Chen, Z. Marsie, and M. Negash, “Temperature and precipitation trend analysis over the last 30 years in southern tigray regional state, Ethiopia," 2017.

[11] A. Philip, Y. Augustine, and B. Abindaw, "Impact of climate variability of small-holder households and indigenous coping strategies in Bongo district," International Journal of Water Resources Development, vol. 4, no. 3, pp. 693-699, 2014, https://www.journalijdr.com.

[12] S. Addisu, Y. G. Selassie, G. Fissha, and B. Gedif, "Time series trend analysis of temperature and rainfall in lake Tana Sub-basin, Ethiopia," Environmental System Research, vol. 4, p. 25, 2015.

[13] J. M. Collins, "Temperature variability over Africa," Journal of Climate, vol. 24, pp. 3646-3666, 2011. 
[14] World Bank, Economics of Adaptation to Climate Change. Ghana Country Study, World Bank, Washington, DC, USA, 2010, https:// documents.worldbank.org/curated/en/646291468171244256/pdf/ 702670ESW0P10800EACCSynthesisReport.pdf.

[15] Environmental Protection Agency, Climate Change andGhanaian Economy, vol. 1, Environmental Protection Agency of Ghana, Accra, Ghana.

[16] A. Issahaku, B. B. Campion, and R. Edziyie, "Rainfall and temperature changes and variability in the Upper East region of Ghana," Earth and Space Science, vol. 3, pp. 284-294, 2016.

[17] G. Jung and H. Kunstmann, "High-resolution climate modelling for the Volta region of West Africa, journal of," Geophysics Research, vol. 112, p. D23108, 2007.

[18] C. N. McSweeney, M. New, and G. Lizcano, UNDP Climate Change Country Profiles-Ghana, 2012, https://ncp.undp.org/ documents/undp-climate-change-country-profile-11.

[19] S. Wiredu, S. Nasiry, and Y. G. Asamoah, "Proposed seasonal aurtoregressive integrated moving average model for forcasting rainfall pattern in the Navrongo Muniicpality, Ghana," Journal of Environment and Earth Science, vol. 3, no. 12, pp. 80-85, 2013.

[20] K. Frimpong, J. Oosthuizen, and E. J. Van Etten, "Recent trends in temperature and relative humidity in Bawku East, Northern Ghana," Journal of Geography and Geology, vol. 6, no. 2, pp. 69-81, 2014.

[21] Ministry of Food and Agriculture, Physical and Natural Environment, Ministry of Food and Agriculture, Accra, Ghana, 2015, http://mofa.gov.gh/site.?page_id=1642.

[22] M. Javari, "Trend and homogeneity analysis of precipitation in Iran," Climate, vol. 4, no. 3, p. 44, 2016.

[23] Ghana Statistical Service, 2010 Population and Housing Census: District Analytical Report for Bawku Municipal, Ghana Statistical Service, Accra, Ghana, 2014, https://new-ndpcstatic1.s3.amazonaws.com/CACHES/PUBLICATIONS/2016/ 06/06/Bawku+Municipality+2010PHC.pdf.

[24] Ghana Statistical Service, 2010 Population and HousingCensus: District Analytical Report for Garu-empane District, Ghana Statistical Service, Accra, Ghana, 2014, http:// www2.statsghana.gov.gh/docfiles/2010_District_Report/Upper \%20East/GARU\%20TEMPANE.pdf.

[25] Cartography Unit, Study Area in Regional and National Context, Department of Geography and Regional Planning, University of Cape Coast, Cape Coast, Ghana, 2019.

[26] K. Owusu and P. R. Waylen, "The changing rainy season climatology of mid-Ghana," Theory of Applied Climatology, vol. 112, pp. 419-430, 2013.

[27] Ghana Statistical Service, 2010 Population and HousingCensus: Summary Report of Final Results, GSS, Sakoa Press Limited, Accra, Ghana, 2012, http://www.statsghana. gov.gh/gssmain/storage/img/marqueeupdater/Census2010_ Summary_report_of_final_results.pdf.

[28] A. Ghasemi and S. Zahediasl, "Normality tests for statistical analysis: a guide for non-statisticians," International Journal of Endocrinology \& Metabolism, vol. 10, no. 2, pp. 486-489, 2012.

[29] H. Alexandersson, "A homogeneity test applied to precipitation data," Journal of Climatology, vol. 6, no. 6, pp. 661-675, 1986.

[30] N. H. Ahmad and S. M. Deni, "Homogeneity test on daily rainfall series for Malaysia," Matematika, vol. 29, no. 1c, pp. 141-150, 2013.

[31] D. C. Edwards and T. B. McKee, "Characteristics of 20th century drought in the United States at multiple timescales,"
Atmospheric Science Paper, vol. 634, pp. 1-30, 1997, https:// hdl.handle.net/10217/170176.

[32] T. B. McKee, N. J. Doesken, and J. Kleist, "The relationship of drought frequency and duration to time scale," in Proceedings of the Eighth Conference on Applied Climatology, pp. 179-184, January 1993, https://www.droughtmanagement.info/ literature/AMS_Relationship_Drought_Frequency_Duration_ Time_Scales_1993.pdf.

[33] P. Angelidis, F. Maris, N. Kotsovinos, and V. Hrissanthou, "Computation of drought index SPI with alternative distribution functions," Water Resource Management, vol. 26, no. 9, pp. 2453-2473, 2012.

[34] N. B. Guttman, "Accepting the standardized precipitation index: a calculation algorithm," Journal of the American Water Resources Association, vol. 35, no. 2, pp. 311-322, 1999.

[35] A. Loukas, L. Vasiliades, and J. Tzabiras, "Climate change effects on drought severity," Advance Geoscience, vol. 17, pp. 23-29, 2008.

[36] A. K. Mishra and V. P. Singh, "Analysis of drought severityarea- frequency curves using a general circulation model and scenario uncertainty," Journal of Geophysics Research, vol. 114, p. D06120, 2009.

[37] G. Tsakiris and H. Vangelis, "Towards a drought watch system based on spatial SPI," Water Resource Management, vol. 18, no. 1, pp. 1-12, 2009.

[38] D. Tigkas, H. Vangelis, and G. Tsakiris, "Drought characterisation based on an agriculture-oriented standardised precipitation index," Theoretical and Applied Climatology, vol. 135, pp. 1435-1447, 2018.

[39] World Meteorological Organisation, Standardized Precipitation Index Use Guide, WMO, Geneva, Switzerland, 2012, http://www.wamis.org/agm/pubs/SPI/WMO_1090_EN.pdf.

[40] I. Nalbantis and G. Tsakiris, "Assessment of hydrological drought revisited," Water Resource Management, vol. 23, pp. 881-897, 2009.

[41] D. Tigkas, H. Vangelis, and G. Tsakiris, "DrinC: software for drought analysis based on drought indices," Earth Science Information, vol. 8, no. 3, pp. 697-709, 2015.

[42] G. Tsakiris, A. Loukas, D. Pangalou et al., "Drought characterisation," in Drought Management Guidelines Technical Annex. Options Méditerranéennes, series B, et al. no. 58, pp. 85-102, Ciheam, Zaragoza, Spain, 2007.

[43] D. ., K. Karpouzos, S. Kavalieratau, and C. Babajimopoulos, "Trend analysis of precipitation data in Piera Region (Greece)," European Water Resources Association, vol. 30, pp. 31-40, 2010, https://www.ewra.net/ew/pdf/EW_2010_30_ 04.pdf\%20\%20, https://www.ewra.net/ew/pdf/EW_2010_30_ 04.pdf, https://www.ewra.net/ew/pdf/EW_2010_30_04.pdf.

[44] P. Antwi-Agyei, A. J. Dougill, and L. C. Stringer, "Barriers to climate change adaptation: evidence from northeast Ghana in the context of a systematic literature review," Climate and Development, vol. 7, no. 4, pp. 297-309, 2015.

[45] K. Owusu and P. Weylen, "Trends in spatio-temporal variability in annual rainfall in Ghana (1951-2000)," Weather, vol. 64, no. 5, pp. 115-120, 2009.

[46] M. Baidu, "Assessment of long-term spatio-temporal rainfall variability over Ghana using wavelength analysis," Thesis submitted to the Department of Physics, Kwame Nkrumah University of Science and Technology, Kumasi, Ghana, 2016.

[47] R. B. Bunnet and P. O. Okunrotifa, General Geography in Diagrams for West Africa, Longman Group Limited, Blantyre Printing \& Binding Co Ltd, Glasgow, Scotland, 1984. 
[48] B. Sultan and S. Janicot, "The West African Monsoon dynamics. Part II: the "preonset" and "onset" of the summer monsoon," J Climate, vol. 16, no. 21, pp. 3407-3427, 2003.

[49] E. Tachie-Obeng, E. Gyasi, S. Adiku, M. Abekoe, and G. Ziervogel, "Farmers 'adaptation Measures in Scenarios of Climate Change for Maize Production in Semi-arid Zones of Ghana," in Proceedings of the 2nd International Conference: Climate, Sustainability and Development in Semi-arid Regions, Fortaleza, Brazil, 2010.

[50] S. Mudombi and M. Muchie, "Perceptions of water access in the context of climate change by rural households in the Seke and Murewa districts, Zimbabwe: original research," Jàmbá: Journal of Disaster Risk Studies, vol. 5, no. 1, pp. 1-8, 2013.

[51] C. N. McSweeney, G. Lizcano, M. New, and X. Lu, "The UNDP climate change country profiles: improving the accessibility of observed and projected climate information for studies of climate change in developing countries," Bulleting of American Meteorological Society, vol. 91, no. 2, pp. 157-166, 2010, http://ncp.undp.org/documents/undp-climate-changecountry-profile- 11 .

[52] M. F. Tshiala, J. M. Olwoch, and F. A. Engelbrecht, "Analysis of temperature trends over Limpopo province, South Africa," Journal of Geography and Geology, vol. 3, no. 1, pp. 13-21, 2011. 